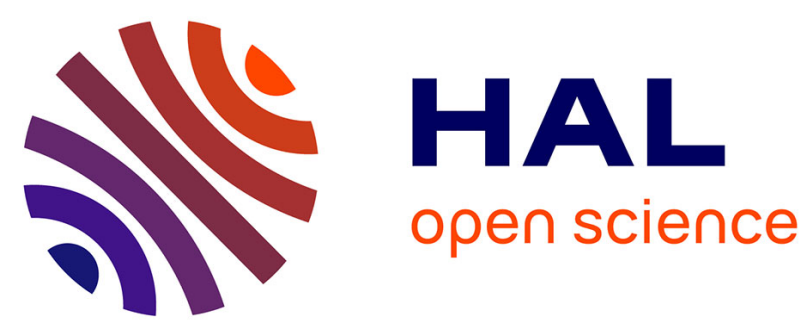

\title{
Oxetanes and Oxetenes: Fused-ring Derivatives
}

Nicolas Blanchard, Vincent Bizet, Nicolas Brach, Lénaïc Rummler, Krishna P Kaliappan

\section{To cite this version:}

Nicolas Blanchard, Vincent Bizet, Nicolas Brach, Lénaïc Rummler, Krishna P Kaliappan. Oxetanes and Oxetenes: Fused-ring Derivatives. Reference Module in Chemistry, Molecular Sciences and Chemical Engineering, Elsevier, 2021, 10.1016/B978-0-12-818655-8.00150-5 . hal-03358269

\section{HAL Id: hal-03358269 \\ https://hal.science/hal-03358269}

Submitted on 29 Sep 2021

HAL is a multi-disciplinary open access archive for the deposit and dissemination of scientific research documents, whether they are published or not. The documents may come from teaching and research institutions in France or abroad, or from public or private research centers.
L'archive ouverte pluridisciplinaire HAL, est destinée au dépôt et à la diffusion de documents scientifiques de niveau recherche, publiés ou non, émanant des établissements d'enseignement et de recherche français ou étrangers, des laboratoires publics ou privés. 


\title{
2.06
}

\section{Oxetanes and Oxetenes: Fused-ring Derivatives}

\author{
Authors: \\ Corresponding Author: \\ Nicolas Blanchard \\ Université de Haute-Alsace, Université de Strasbourg, CNRS, LIMA UMR 7042, Mulhouse, France \\ n.blanchard@unistra.fr
}

Co-Authors:

Vincent Bizet

Université de Haute-Alsace, Université de Strasbourg, CNRS, LIMA UMR 7042, Mulhouse, France vbizet@unistra.fr

Nicolas Brach

Université de Haute-Alsace, Université de Strasbourg, CNRS, LIMA UMR 7042, Mulhouse, France Nicolas.brach@etu.unistra.fr

Lénaïc Rummler

Université de Haute-Alsace, Université de Strasbourg, CNRS, LIMA UMR 7042, Mulhouse, France $\underline{\text { Lenaic.rummler@etu.unistra.fr }}$

Krishna P. Kaliappan

Department of Chemistry, Indian Institute of Technology Bombay, Powai, Mumbai 400076, India kpk@chem.iitb.ac.in

\section{Abstract}

Fused and spiro-oxetanes, oxetenes and $\beta$-lactones are important classes of compounds that have found numerous applications in various areas of chemistry including medicinal chemistry and total synthesis of natural products. In this chapter, the main achievements from the theoretical and synthetic point of views since its last edition are discussed.

\section{Keywords}

Fused oxetane; Fused oxetene; Spiro-oxetane; Spiro-oxetene; $\beta$-Lactone; Spiro- $\beta$-Lactone; Heterocycles; Four-Membered rings.

\subsubsection{Introduction}

This chapter reviews developments related to fused and spiro-oxetanes, oxetenes and $\beta$-lactones from 2008 to mid-2020. Their physical properties, the methods for their synthesis, their reactivity trends and their applications to the preparation of biologically relevant compounds are discussed. 


\subsubsection{Theoretical Methods}

A physical organic chemistry study of the photochemical generation of ortho-naphthoquinone methides $\mathbf{5}$ from 1 and their reactivity in aqueous solution was reported by Arumugam and Popik. ${ }^{1}$ Naphthoxete $\mathbf{3}$ was proposed as intermediate in the formation of ortho-naphthoquinone methide by irradiation of 3-hydroxy-2-naphthalenemethanol 1. The ring opening of naphthoxete $\mathbf{3}$ is a thermal reaction, slower than the decay of the excited state of $2 \mathbf{a}$. All structures were investigated at the (B3LYP/6-311++G(d,p)//B3LYP/6-31++G(d,p) and MP2/6-31++G(d,p)//FC-MP2/6-31++G(d,p) levels of theory.<smiles>Oc1cc2ccccc2cc1CP</smiles>

$1 \mathrm{a}, \mathrm{R}=\mathrm{OH}$

1b, $R=O E t$

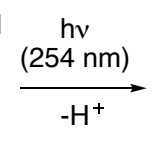

$-H^{+}$

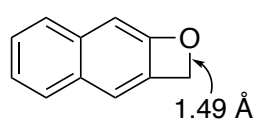

3<smiles>C=C1C=c2ccccc2=CC1=O</smiles>

$<$ Scheme 1 near here>

1,8-Peribridged naphthalenes are highly strained structures that are often unstable although a few molecules have succumbed to X-ray diffraction. Novak reported ring strain energies (RSE) of series of single atom peribridged naphthalenes (SAPN) using high level quantum chemical methods. SAPN 6 has the highest RSE of $289.7 \mathrm{~kJ} / \mathrm{mol}$. A comparison was also proposed with compounds $\mathbf{3}, \mathbf{7}$ and $\mathbf{8}$ possessing a fused-oxetene at different positions of a naphthalene core. ${ }^{2}$

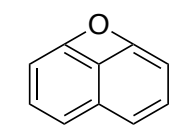

6

$289.7 \mathrm{~kJ} / \mathrm{mol}$

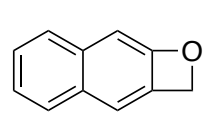

3

140.6

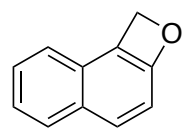

7

137.3<smiles>c1ccc2c3c(ccc2c1)CO3</smiles>

7

135.1

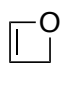

8

109.9

$<$ Scheme 2 near here $>$

Ground state and excited state potential energy surfaces of the photoexcitation of orthohydroxybenzaldehyde have been studied in silico by Migani. ${ }^{3} \mathrm{~A}$ potential product is an oxetene adduct arising from a decay at a twisted-pyramidalized intersection seam, although the barrier for its formation was higher than for other decay products. Oxetenes undergo conrotatory electrocyclic ring opening as demonstrated as early as $1971 .{ }^{4}$ In 2010, Venuvanalingam and Chattaraj reported a quantum chemical mechanical study at the B3LYP level with $6-31 G(d)$ and $6-311+G(d, p)$ basis sets on this kind of perturbed pericyclic isomerizations. ${ }^{5}$ This study proposed hardness indices based on closely lying frontier molecular orbitals that reflect much better the relative reactivity of oxetene and its analogues (phosphetene, thiete and azete). Jayaprakash has reported an ab initio molecular orbital and DFT study of the electrocyclic ring-opening of oxetene in the gas phase. ${ }^{6}$ It was shown 
that this pseudo-pericyclic process was characterized by a more planar transition state and an inferior barrier of activation compared to the electrocyclic ring-opening of cyclobutene.

Ruthenium-catalyzed decarbonylative couplings of aromatic aldehydes and terminal alkynes lead to alkenes, as demonstrated by Li in 2009. ${ }^{7}$ An intramolecular variant was also reported by Saá (using protic acid additives) ${ }^{8}$ and the mechanism of the latter transformation was explored through quantum mechanical calculations by Li. ${ }^{9}$ Recently, Li and Moitessier studied in depth the mechanism of this reaction through computational chemistry and isotope-labeling experiments. Zhang's fused oxetene intermediate was ruled out in favor of an aldol-type reaction of a ruthenium-vinylidene complex. ${ }^{10}$

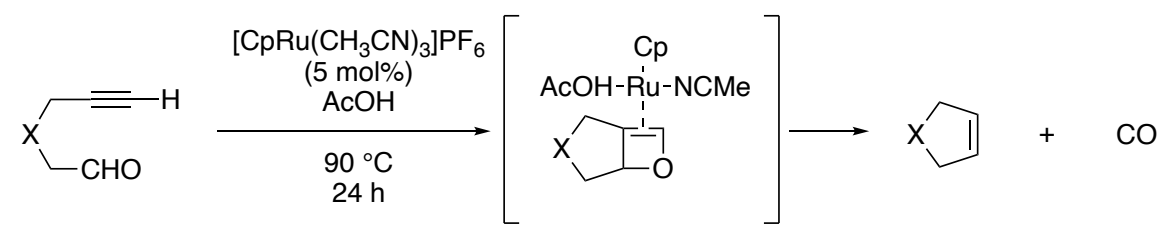

$$
\begin{gathered}
10 \\
\mathrm{X}=\mathrm{C}_{\left(\mathrm{CO}_{2} \mathrm{Me}\right)_{2},}, \\
\mathrm{C}\left(\mathrm{CH}_{2} \mathrm{OR}\right)_{2}, \mathrm{NTs}
\end{gathered}
$$

11

oxetene intermediate
$12,40-93 \%$

$<$ Scheme 3 near here $>$

A detailed study of the directing role of hydroxy functions in the Paternò-Büchi [2+2] photocycloaddition was reported by Abe in 2011. ${ }^{11}$ Through a combination of experimental and theoretical studies, it was shown that cooperative hydrogen-bonding stabilization and steric interactions were crucial.

Fused oxetenes are intermediates in the Fe(III)-catalyzed cyclization of yne-acetals. ${ }^{12} \mathrm{Yu}$ and Li have reported a DFT investigation of the reaction mechanism using the B3LYP method and the $6-311+G^{* *}$ basis set, excluding [2+2] cycloaddition of yne-oxonium $\mathbf{1 3}$ in favor of cyclization of the vinylic carbocation 14 to the fused oxetenium 15 with an activation barrier of $17.2 \mathrm{kcal} / \mathrm{mol}$. These alkyneoxononium reactions are discussed in Section 2.06.6.6.

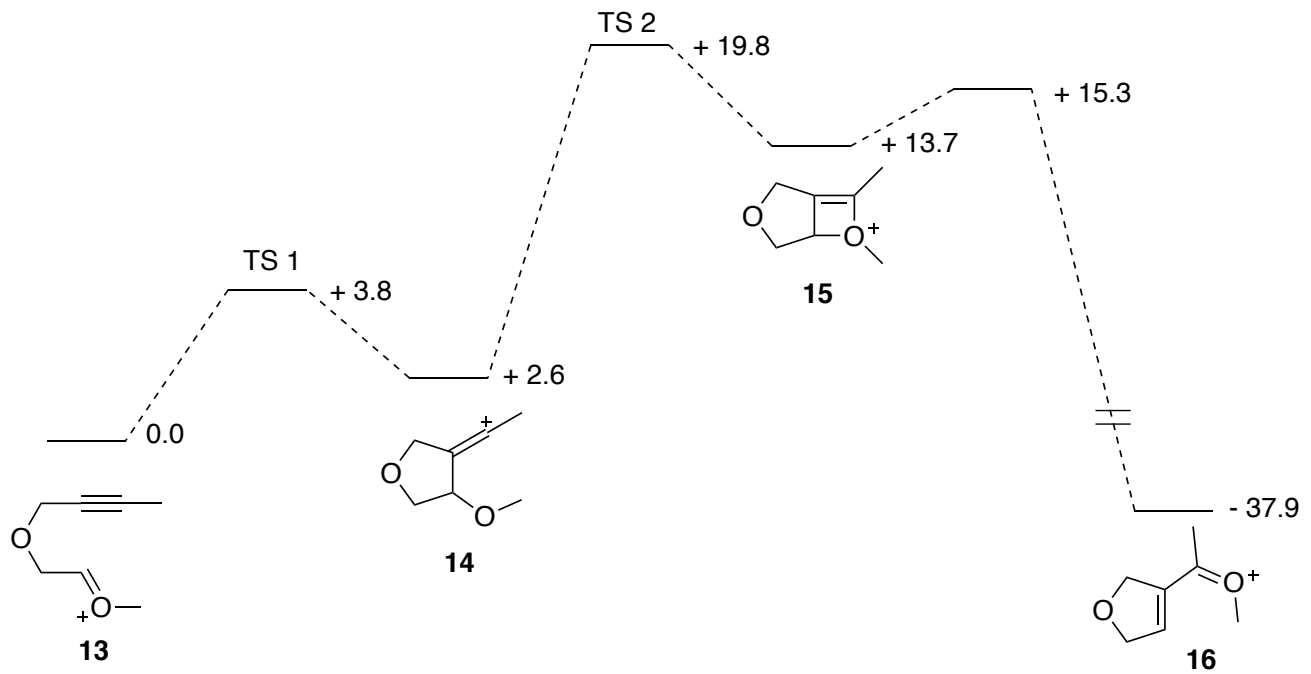

$<$ Scheme 4 near here $>$ 
A parametric/DFT hybrid computational method DU8+ was recently applied to the analysis of published NMR data of naturally occurring oxetanes. ${ }^{13} \mathrm{~A}$ high rate of structure misassignment was found with more than 30 proposed structures requiring revisions, selected examples being highlighted in Section 2.06.11.

\subsubsection{Experimental Structural Methods}

\subsubsection{Electron momentum spectroscopy}

Electron momentum spectroscopy of oxetane was reported by Chen, leading to the binding energy spectra and the electron momentum distribution for the outer-valence molecular orbitals. ${ }^{14,15}$ It was shown that the ring-puckering motion of oxetane has a dramatic influence on the electron density distribution of the highest occupied molecular orbital.

\subsubsection{Electronic and vibrational absorption spectroscopies}

Ashfold reported the use of broadband transient electronic and vibrational absorption spectroscopies for an insightful study of the Paternò-Büchi reaction between benzaldehyde and cyclohexene. ${ }^{16}$ Quantum yields and rates constants for competing pathways were determined.

\subsubsection{IR spectroscopy}

Benzoxetone 19 was formed quite easily from 6-oxocyclohexa-2,4-dienylideneketene 18 by irradiation at $340 \mathrm{~nm}, \mathbf{1 8}$ being prepared by photolysis of $\mathbf{1 7}$ at $315 \mathrm{~nm}$. 19 can reverse to 18 upon photolysis at $315 \mathrm{~nm}$. No differences were observed in the IR spectra of $\mathbf{1 8}$ and $\mathbf{1 9}$ for at least 6 photolysis cycles. ${ }^{17}$<smiles>O=c1ooc(=O)c2ccccc12</smiles>

17

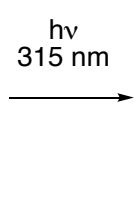<smiles>O=C=C1C=CC=CC1=O</smiles>

18

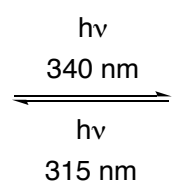
1916, 1904, 1624, 1604, $1443,1340 \mathrm{~cm}^{-1}$

$<$ Scheme 5 near here $>$

Benzoxete chemistry has been reviewed by Meier and the reader is redirected to this excellent article for details related to their isolation and reactivity. ${ }^{18}$ Many erroneous or questionable benzoxetes are also discussed. Other reviews were also recently published. ${ }^{19} 2 \mathrm{H}$-Benz[b]oxetes were first isolated by Tomioka and Matsushita in 1997, by irradiation of orthohydroxyphenyldiazomethane (at $\lambda>300 \mathrm{~nm}$ ) or benzofuranone (at $\lambda>254 \mathrm{~nm}$ ) in an argon matrix at $10 \mathrm{~K} .{ }^{20}$ These highly strained compounds $(38 \mathrm{kcal} / \mathrm{mol})^{21}$ are in valence equilibrium with their orthoquinoid structures, the latter being much more favored from a thermodynamic point of view. Theoretical and experimental IR spectrum of benzoxetes were compared and found in very good agreement. Benzoxete was also detected by irradiation of a vapor deposition prepared sample of 2- 
hydroxymethylphenol at $254 \mathrm{~nm}$ and $14 \mathrm{~K}$. The characteristic signal at $v=1668 \mathrm{~cm}^{-1}$ (scissoring vibration of the $\mathrm{CH}_{2}$ motif) was clearly observed. ${ }^{22}$

\subsubsection{X-ray crystallography}

X-ray crystallographic studies on a range of fused or spiro-oxetanes and $\beta$-lactones have been reported over the period of interest to this chapter, as in the cases of the natural products hawaiinolide $E_{,}{ }^{23}$. hawaiinolide $A$ and $C,{ }^{24}$ aphanalide $A$ and $C,{ }^{25}$ and rubesanolide $A .{ }^{26} \mathrm{X}$-ray structures of various synthetic compounds have also been reported ${ }^{27}$ including fused oxetanes resulting from the photocycloaddition of electronically excited carbonyl to isoxazoles (e.g. 20), ${ }^{28}$ a planar oxetane arising from the Paternò-Büchi reaction of triplet benzophenone with 4 -aryl-4H-pyrans, ${ }^{29}$ an unprecedented tricyclic $3 \mathrm{H}$-oxeto[2,3,4-ij] isochromene featuring a rare oxetane acetal reported in 2017 during the course of synthetic investigations of sigillin A, an insect repellent natural product isolated from springtails. ${ }^{30}$ Spirocyclohexene-oxetanes were prepared through catalytic enantioselective cycloaddition to $\alpha, \beta, \beta$-trisubstituted nitroalkenes, and a single structure $\mathbf{2 1}$ was reported, allowing the assignment of absolute configuration. ${ }^{31}$ Spiro-oxetane embedded in heterocyclic structures have been disclosed recently. ${ }^{32}$ Structures of spiro- $\beta$-lactones prepared via the [2+2] cycloaddition of disubstituted ketenes with isatins, such as $\mathbf{2 2}$, were also characterized by X-ray crystallography. ${ }^{33}$

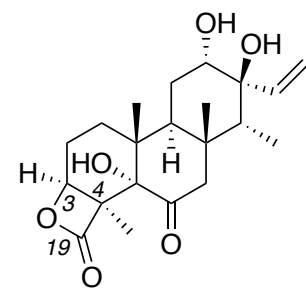

hawaiinolide $E$

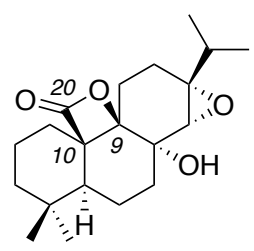

rubesanolide $A$

$\begin{array}{llll}\text { C3-O: } 1.502 \AA & \text { C3: } \delta C 78.6 \mathrm{ppm} & \text { C9-O: } 1.504 \AA & \text { C9: } \delta C 80.4 \mathrm{ppm} \\ \text { C3-C4: } 1.558 \AA & \delta \mathrm{H} 4.32 \mathrm{ppm}(\mathrm{dd}, J 2.7,5.6 \mathrm{~Hz}) & \text { C9-C10: } 1.563 \AA & \text { C10: } \delta C 61.2 \mathrm{ppm} \\ \text { C4-C19: } 1.536 \AA & \text { C4: } \delta C 59.4 \mathrm{ppm} & \text { C10-C20: } 1.517 \AA & \text { C20: } \delta C 174.1 \mathrm{ppm} \\ \text { C19-O: } 1.360 \AA & \text { C19: } \delta C 172.4 \mathrm{ppm} & \text { C20-O: } 1.353 \AA & \end{array}$

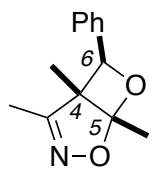

20

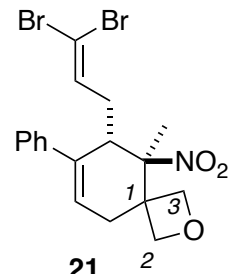

C2-O: $1.445 \AA$

C1-C2: $1.551 \AA$

C1-C3: $1.541 \AA$

C3-O: $1.452 \AA$

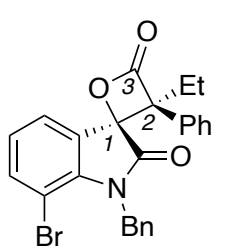

22

C1-O: $1.483 \AA$

C1-C2: $1.556 \AA$

C2-C3: $1.533 \AA$

C3-O: $1.343 \AA$

$<$ Scheme 6 near here> 


\subsubsection{Thermodynamic Aspects}

Oxetanes are prone to ring-opening ${ }^{34}$ under acidic conditions at similar rates than epoxides, ${ }^{35}$ an experimental observation that can be rationalized by their similar ring-strain $(106 \mathrm{~kJ} / \mathrm{mol}$ for oxetanes vs. $112 \mathrm{~kJ} / \mathrm{mol}$ for epoxides). ${ }^{36,37}$ On the other hand, oxetanes are hydrolyzed at slower rates than epoxides under basic conditions. Theoretical studies have addressed this reduction in hydrolysis rates. ${ }^{38-42}$ Strain energies and equilibrium geometries of 2,4-oxytwistane 23 were computed $a b$ initio using the MP2 $(\mathrm{fc}) / 6-31 \mathrm{G}(\mathrm{d})$ theoretical model and compared with oxetane. ${ }^{43}$ The ring-strain energies (RSEs) of spiroepoxy- $\beta$-lactone $\mathbf{2 4}$ and spiroepoxy-oxetane $\mathbf{2 5}$ have been calculated from the energies of fully-optimized structures at the MP2 + ZP/cc-pVDZ level. The stability/reactivity of spiroepoxy- $\beta$-lactone $\mathbf{2 4}$ has been discussed and found to not correlate with RSE. ${ }^{44}$

Gas-phase enthalpies of formation of oxetane $26(-80 \mathrm{~kJ} / \mathrm{mol})$ and oxetene $10(-52.8 \mathrm{~kJ} / \mathrm{mol})$ were determined by high-level quantum chemical calculations at the G3(MP2)//B3LYP level by Taskinen in $2009 .{ }^{45}$ Closely related results were reported by Green in 2012 using an application of a QCISD(T) quantum chemistry strategy. ${ }^{46}$

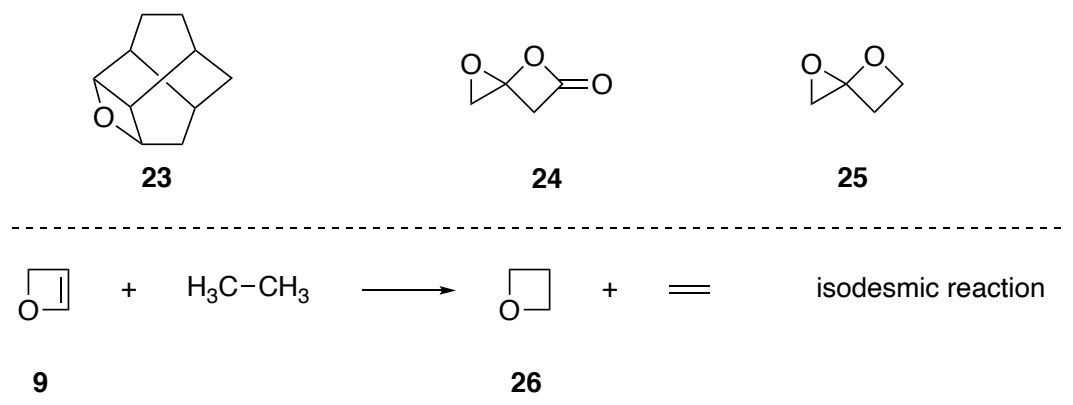

$<$ Scheme 7 near here>

\subsubsection{Reactivity of Fully Conjugated Rings}

No examples of this class of compounds have been found in the literature in the period covered.

\subsubsection{Reactivity of Nonconjugated Rings}

\subsubsection{Reaction with Nucleophiles}

As shown by Carreira and Roger-Evans, ${ }^{47-50}$ oxetanes are relevant bioisosters for gem-dimethyl substituents or carbonyl groups. $\alpha$-Functionalization of oxetan-3-ones can be conveniently performed using Enders' SAMP/RAMP synthetic methodology ${ }^{51}$ as shown by Shipman. ${ }^{52}$ Hydrazone $\mathbf{2 8}$ was obtained in $68 \%$ yield and could be further hydrolyzed to the fused oxetane $\mathbf{2 9}$ in $60 \%$ yield and $84 \%$ enantiomeric excess.

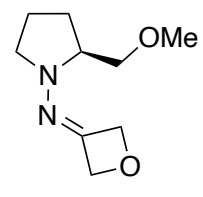

27

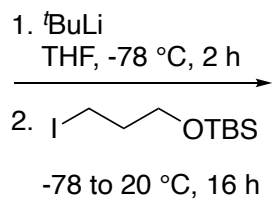

-78 to $20^{\circ} \mathrm{C}, 16 \mathrm{~h}$

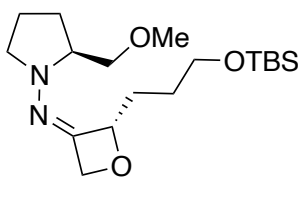

$28,68 \%$

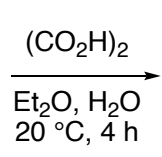

$29,60 \% 84 \%$ ee 
Bode introduced the SnAP (stannyl (Sn) amine protocol) concept for the rapid synthesis of diversely substituted heterocycles from stannyl methylether and aldehydes or ketones. ${ }^{53-55}$ SnAP reagent 30 serves as a cross-coupling partner with 3-quinolinecarboxaldehyde $\mathbf{3 1}$, leading to $\mathbf{3 2}$ in $56 \%$ yield. ${ }^{56}$<smiles>CCCCCCCCCCCCCCCCCCCCCC</smiles>

30<smiles>O=Cc1cnc2ccccc2c1</smiles>

31

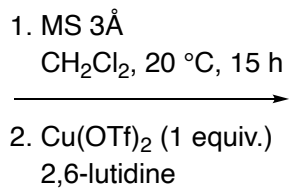

$\mathrm{CH}_{2} \mathrm{Cl}_{2} / \mathrm{HFIP}(4: 1)$ $20^{\circ} \mathrm{C}, 15 \mathrm{~h}$<smiles>c1ccc2ncc(C3COCC4(COC4)N3)cc2c1</smiles>

$32,56 \%$

$<$ Scheme 9 near here>

Spiro-oxetanes can be obtained using classical Pictet-Spengler cyclization of L-tryptophan ethyl ester $\mathbf{3 3}$ and oxetan-3-one $\mathbf{3 4}$ using iodine in hot acetonitrile. Spiro-oxetane $\mathbf{3 5}$ was obtained in $\mathbf{7 6 \%}$ as a mixture of two diastereomers $(\mathrm{dr}=88: 12) .^{52}$<smiles>NC(Cc1c[nH]c2ccccc12)C(=O)O</smiles>

33<smiles>O=C1CO[C@@H]1Br</smiles>

$34,74 \%$ ee

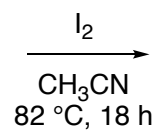
$82^{\circ} \mathrm{C}, 18 \mathrm{~h}$<smiles>O=C(Br)C1CCCC2c3ccccc3NC12</smiles>

$35,76 \%, d r=88: 12$

$<$ Scheme 10 near here>

Fused N,O-acetals of oxetan-3-one, such as 36, can be transformed into a myriad of interesting heterocyclic scaffolds via the addition of carbon-based nucleophiles. As an example, Carreira showed that potassium trifluoroorganoborates were competent partners under Lewis acid catalysis leading to oxetanes such as $\mathbf{3 7}$ containing a quaternary center. ${ }^{57}$ The pendant alcohol function can then cyclize onto the oxetane, leading to morpholines (e.g. 38) by ring-expansion. Introduction of cyanide as a nucleophile is also possible, using trimethylsilyl cyanide under indium triflate catalysis in acetonitrile. $^{58}$

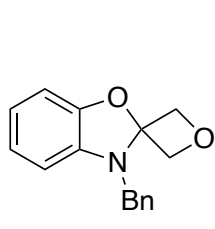

36

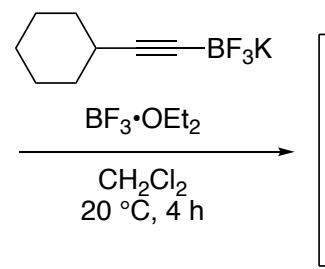

$20^{\circ} \mathrm{C}, 4 \mathrm{~h}$

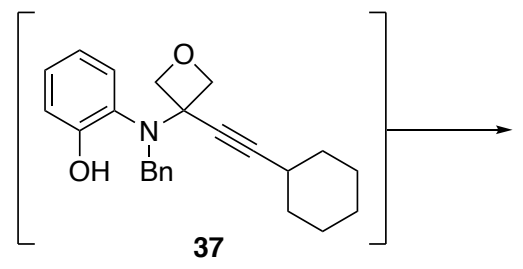

37

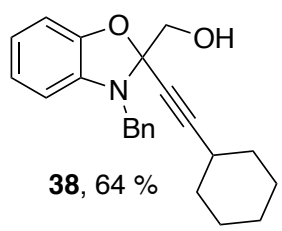

<Scheme 11 near here> 
Spirocyclohexene-oxetanes were obtained by Jørgensen via an impressive catalytic enantioselective [4+2] cycloaddition of $\alpha, \beta, \beta$-trisubstituted nitroolefin $\mathbf{4 0}$ with $\alpha, \beta, \gamma, \delta$-unsaturated aldehyde $39 .{ }^{31}$ The reaction proceeds through trienamine organocatalysis ${ }^{59}$ and delivers a broad range of spirocyclic oxetanes, such as $\mathbf{4 1}$, containing two contiguous stereogenic centers including a quaternary one. It should be pointed out that the exact mechanism is still a matter of debate, whether being a pericyclic or a stepwise process. ${ }^{59,60}$

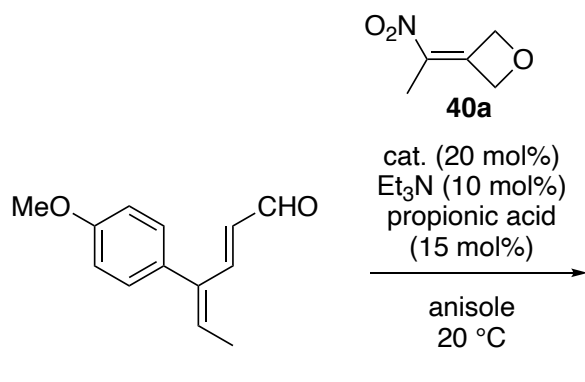

39

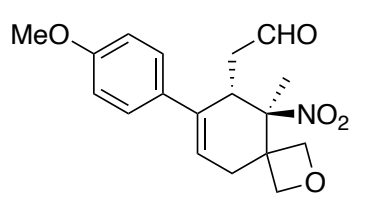

$41,82 \%, d r>20: 1,93 \%$ ee

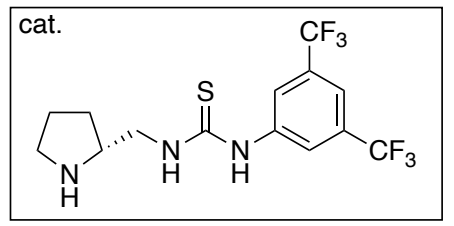

$<$ Scheme 12 near here $>$

Intramolecular [4+2] cycloaddition reactions of sydnones $\mathbf{4 4}$ have been reported by Harrity as an efficient tool to prepare spiro-oxetane containing fused pyrazoles such as compound $\mathbf{4 5}$ obtained in $93 \%$ yield. Cycloaddition precursor $\mathbf{4 4}$ itself is prepared in a straightforward sequence from sydnone 42 and 3-oxetanone $43 .{ }^{61}$

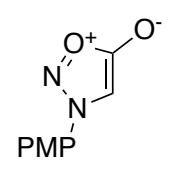

42

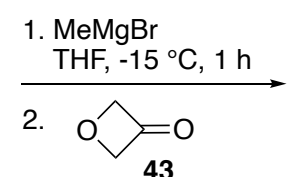

-15 to $20^{\circ} \mathrm{C}, 5 \mathrm{~h}$

3. $\mathrm{KH}$

TBAI (10 mol\%)

propargyl bromide

THF

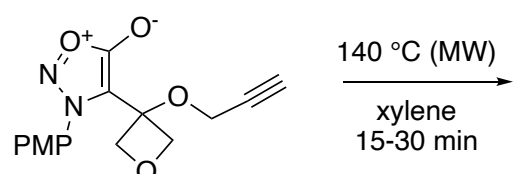

44, $47 \%$

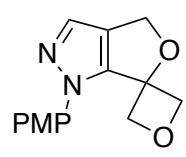

$45,93 \%$

$<$ Scheme 13 near here $>$

4- $\pi$-Photocyclization of 2-pyrone, a process reported for the first time in 1964, leads to a valuable bicyclic $\beta$-lactone ${ }^{62}$ whose chemistry has been reviewed early 2020 by Coote. ${ }^{63}$ Selected examples over the 2008-2020 period demonstrate the versatility of this building block for the straightforward synthesis of relevant cyclobutenes or cyclobutanes. ${ }^{64-72}$

\subsubsection{Elimination}

Elimination of spiro-oxetanes is a facile process that has been central to the synthesis of homoallylic alcohols. Catalytic processes have also been reported, such as the tris(pentafluorophenyl)boranecatalyzed isomerization of 2,2-disubstituted oxetanes $\mathbf{4 6}$ or $\mathbf{4 8}$. Under very mild conditions $\mathbf{0 . 5}$ mol\% of Lewis acid, room temperature, short reaction times), good yields of the desired homoallylic products 47 and 49 were obtained. ${ }^{73}$ 


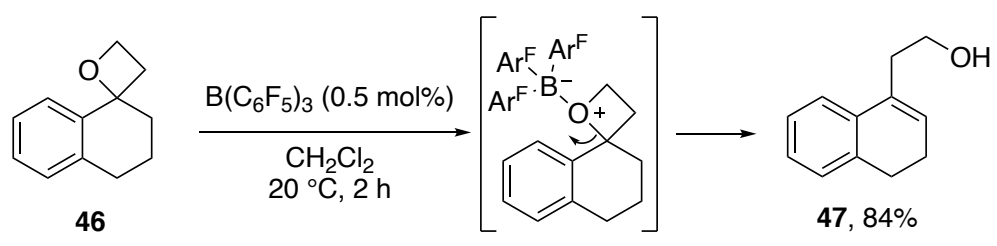

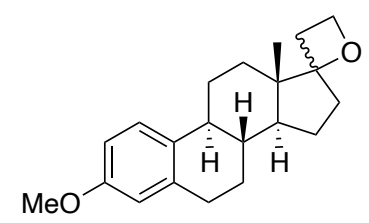

48

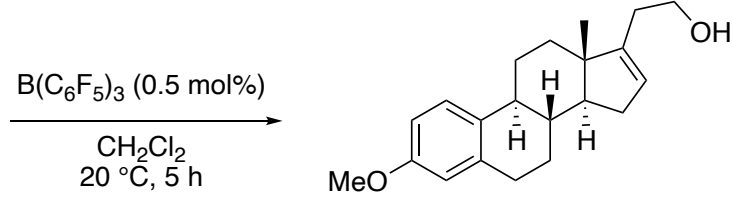

$49,78 \%$

$<$ Scheme 14 near here>

\subsubsection{Ring Expansion}

Ghosh reported the synthesis of high-affinity P2 ligand for HIV-1 protease inhibitors such as (-)-52 using a short synthetic sequence relying on the Paternò-Büchi photoadduct ( \pm )-50. Hydrogenation of the latter followed by an acid-catalyzed transacetalization using para-toluenesulfonic acid in warm methanol delivered $( \pm)-51$ in good yield. ${ }^{74}$

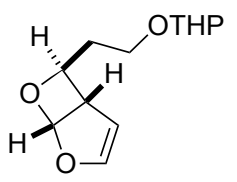

$( \pm)-50$

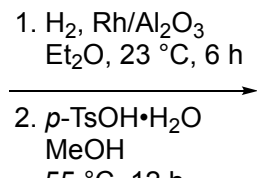

$55^{\circ} \mathrm{C}, 12 \mathrm{~h}$

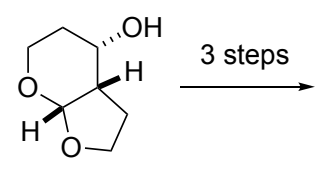

$( \pm)-51,63 \%$<smiles>COc1ccc(S(=O)(=O)N(CC(C)C)C[C@H](O)[C@H](Cc2ccccc2)NC(=O)O[C@H]2CCO[C@@H]3OCC[C@H]23)cc1</smiles>

HIV Protease inhibitor (-)-52, 37\%

$<$ Scheme 15 near here>

3-Oxetanone 43 has been introduced as a versatile building block for medicinal chemistry. The corresponding aminals, hemiaminals and hemithioacetals $\mathbf{5 3}$ were found to react with trimethylsilyl cyanide and a catalytic amount of indium(III) triflate in acetonitrile at room temperature in a smooth ring-expansion process, going through postulated intermediate 54. The functional group tolerance of this cascade reaction is quite large and morpholines, thiomorpholines and piperazines $\mathbf{5 5}$ were obtained in moderate to excellent yields and diastereoselective ratios. ${ }^{58}$ 


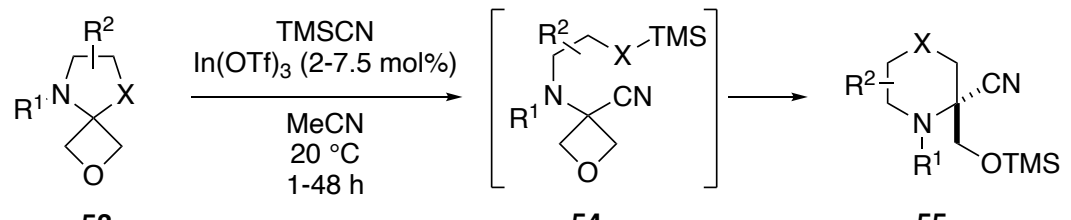

$$
\mathrm{X}=\mathrm{N}, \mathrm{O}, \mathrm{S}
$$

55a, $99 \%$<smiles>CCN1CCN([As])C[C@@]1(CN)CO[Na]</smiles>

55d, $67 \%$<smiles>COC[C@@]1(C#N)CO[C@H](COc2ccccc2)CN1Cc1ccccc1</smiles>

55b, $79 \%(d r=12: 1)$<smiles>[3H]N1CC([Se][Te])N(Br)[C@](C#N)(CO)C1</smiles>

55e, $54 \%(d r>20: 1)$ (after treatment with $\mathrm{BF}_{3} \cdot \mathrm{OEt}_{2}$ )

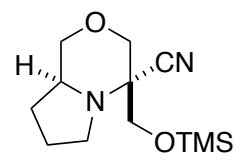

$55 c, 67 \%(d r>20: 1)$<smiles>COC[C@@]1(CN)CSCC(Cc2ccccc2)N1Cc1ccccc1</smiles>

$55 f, 89 \%(d r=2: 1)$

<Scheme 16 near here>

\subsubsection{Reduction}

Photoadduct 56, arising from a Paternò-Büchi reaction between benzaldehyde and trimethylsilyloxycyclopentene, was found to undergo clean reduction to the corresponding tertiary alcohol $\mathbf{5 7}$ or a regioselective rearrangement to cyclohexanone $\mathbf{5 8}$ via an aluminum(III)-mediated pinacol type process. $^{75}$<smiles>CO[C@]12CCC[C@H]1O[C@H]2c1ccccc1</smiles>

56<smiles>CO[C@]12CCC[C@H]1O[C@H]2c1ccccc1</smiles>

56

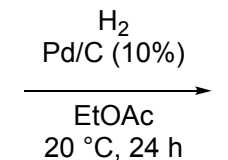

$20^{\circ} \mathrm{C}, 24 \mathrm{~h}$

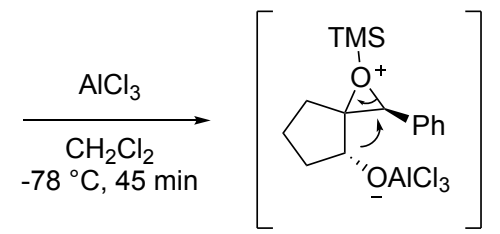

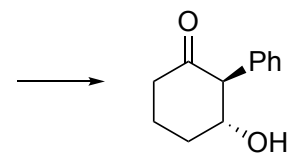

58, $70 \%$

$<$ Scheme 17 near here>

One step reduction of $\beta$-lactones 59 to oxetanes 60 has not been reported in the literature, which prompted the development of a 2-step sequence implying reduction to the diol followed by cyclization under basic conditions. ${ }^{76}$ The first step of the process turned out to be quite difficult, leading to decomposition via retro-aldol reactions. Finally, diisobutylaluminium hydride in dichloromethane proved to be the best reducing agent after an extensive screening. Cyclization 
reaction of the diol could be efficiently promoted by tosyl chloride and potassium tert-butoxide in refluxing tetrahydrofuran.

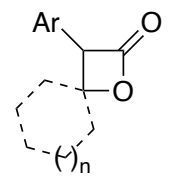

$59, \mathrm{n}=3-6$

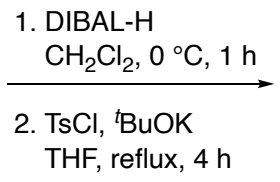

THF, reflux, $4 \mathrm{~h}$

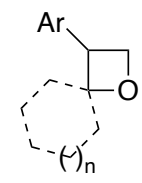

60

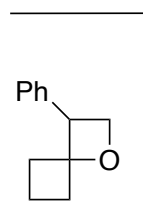

60 a, $67 \%$

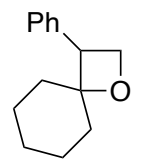

60b, $65 \%$

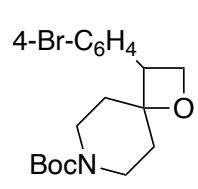

60 c, $75 \%$

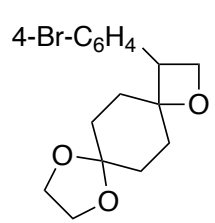

$60 d, 44 \%$

$<$ Scheme 18 near here>

\subsubsection{Cycloreversion}

Cycloreversion of oxetanes has been comprehensively reviewed in 2019. ${ }^{77}$ Decarboxylation of $\beta$-lactone ${ }^{78}$ is a fundamental process in organic synthesis that has been exploited by Chi in 2017. Fused $\beta$-lactone $\mathbf{6 1}$ could be transformed into the corresponding epoxide $\mathbf{6 2}$ without any loss in enantiopurity, via a decarboxylation in DMF at $110^{\circ} \mathrm{C}$ followed by epoxidation with $m$-CPBA. ${ }^{79}$

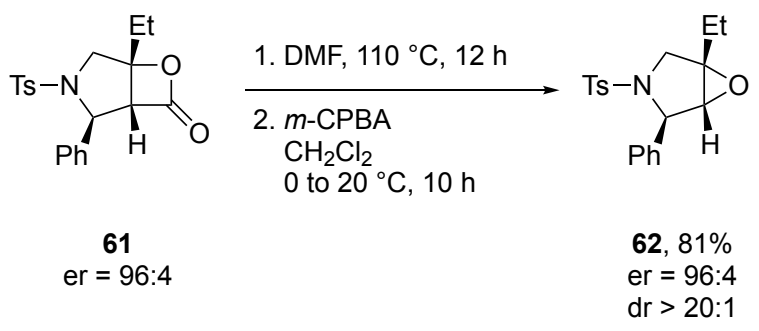

$<$ Scheme 19 near here>

\subsubsection{Alkyne-Carbonyl Metathesis}

Carbonyl-alkyne metathesis reactions are powerful tools to build in a straightforward manner $\alpha, \beta$-unsaturated carbonyls through the cycloreversion of oxetenes intermediates. ${ }^{80-85}$ As evocated before, metal-catalyzed cyclization reactions of $\omega$-alkynyl carbonyls constitute efficient transformations for the synthesis of $\alpha, \beta$-unsaturated ketones or aldehydes. As an example, Yamamoto ${ }^{86}$ reported the gold-catalyzed carbocyclization ${ }^{87}$ of a series of internal ketones 63 that delivered enones $\mathbf{6 6}$ in good to excellent yields. The fused carbocationic oxetane 65, arising from the $\pi$-activation of the alkyne followed by cyclization of the carbonyl, is postulated as an intermediate. 


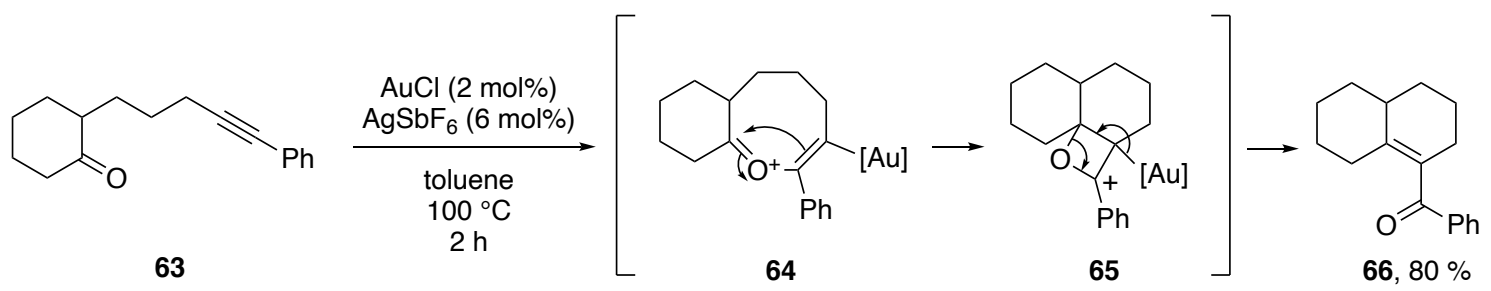

$<$ Scheme 20 near here $>$

Yu and Li reported a Fe(III)-catalyzed cyclisation of yne-acetal 67 that proceeds via fused oxetenium 70. ${ }^{12}$ Ring opening of the latter followed by hydrolysis of the oxocarbenium leads to $\alpha, \beta$-unsaturated ketones 68. A dramatic solvent effect was found, and nitromethane or acetone delivered the highest yields. The alkynyl motif could be substituted by aromatic, alkyl, vinyl or alkynyl groups with the same efficiency. Intermolecular versions are also possible as exemplified by the Fe(III)-catalyzed transformation of alkyne $\mathbf{7 2}$ into $\alpha, \beta$-unsaturated ketone $\mathbf{7 4}$.

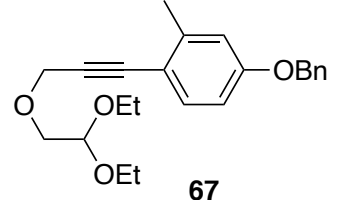

67
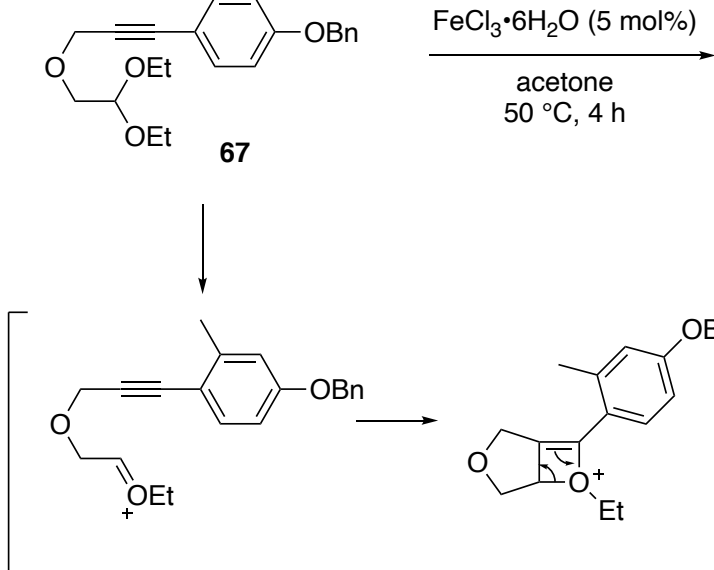

69

70<smiles>CCCCCCCCCOc1ccc(C(=O)C2=CCOC2)c(C)c1</smiles>

$68,92 \%$<smiles>CCOc1ccc(C(=O)c2ccc(OCC)cc2C(=[O+])c2ccc(OCC)cc2C)c(C)c1</smiles>

71

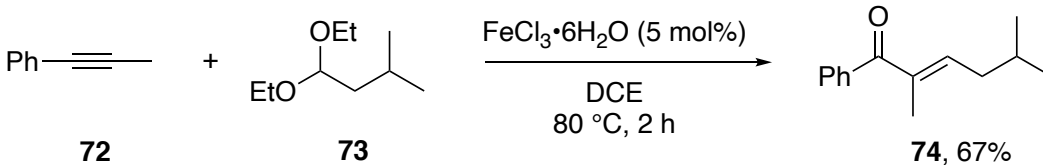

$<$ Scheme 21 near here>

Saá reported the easy preparation of hydroazulenones $\mathbf{7 6}$ and $\mathbf{7 7}$ from the corresponding acyclic enyne acetals 75 using tetrafluoroboric acid in dichloromethane at $0{ }^{\circ} \mathrm{C} .{ }^{88}$ The scope of the transformation is quite large and the reaction is postulated to go through formation of oxonium 78, followed by alkyne-oxonium metathesis. The fused O-substituted oxetenium $\mathbf{7 9}$ would then undergo an electrocyclic ring-opening to the divinyl ketone 80. Subsequent Nazarov electrocyclization and proton elimination would then deliver the observed products. A dramatic influence of the starting material alkene substitution on the regioselective course of the process was found. 


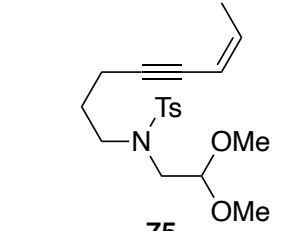

75

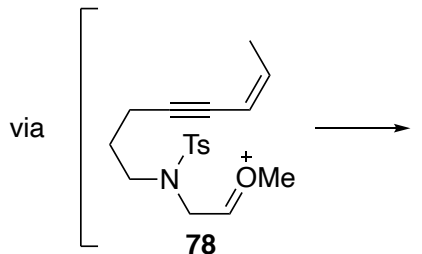

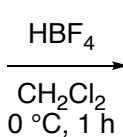

$0{ }^{\circ} \mathrm{C}, 1 \mathrm{~h}$<smiles>CC1CC(=O)C2=C1CN([13F])CCC2</smiles>

76 $80 \%, 76 / 77=2: 1$<smiles>C/C=C\C(=O)C1=CCN([As])CCC1</smiles>

80

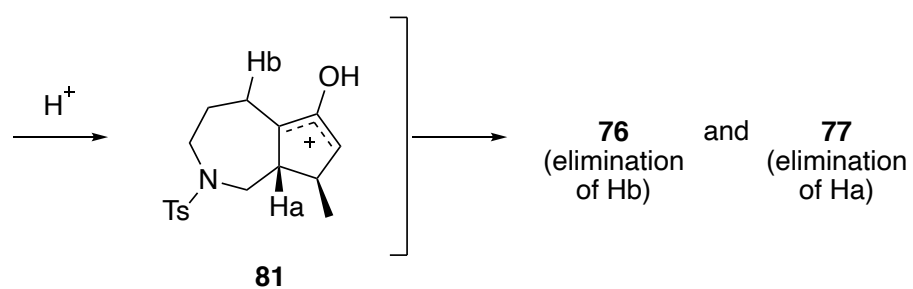

$<$ Scheme 22 near here $>$

Silylated fused oxeteniums 85 were postulated as precursors to $\alpha, \beta$-unsaturated ketones en route to 3,4-disubstitued pyrroles $\mathbf{8 3 .}{ }^{89}$ Initial semi-pinacol rearrangement leads to a ring-contracted intermediate $\mathbf{8 4}$ which undergoes an alkyne-ketone metathesis yielding the substituted pyrrole after spontaneous oxidation.<smiles>CN(CC#Cc1ccccc1)CC12CC(C)(O1)C(C)(C)CC2=O</smiles>

82

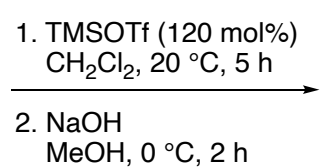

$\mathrm{MeOH}, 0{ }^{\circ} \mathrm{C}, 2 \mathrm{~h}$

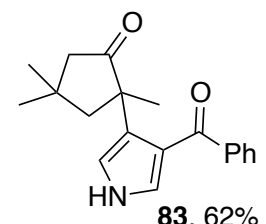

$83,62 \%$

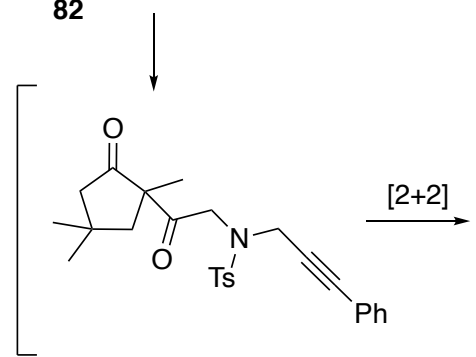

84

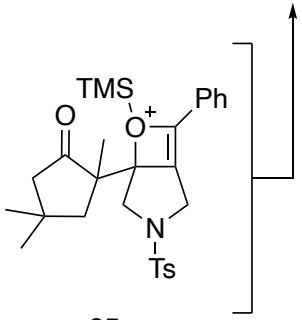

85

$<$ Scheme 23 near here>

Fused oxetenium ions are intermediates in the synthesis of medium and large ring lactones from acetals and silylated ynol ethers. Sun reported that treating acetal $\mathbf{8 6}$ with a Lewis acid in the presence of 2,4,6-collidine led to the formation of oxocarbenium such as $\mathbf{9 1}$ that underwent a spontaneous electrocyclic ring-opening to $8 .^{90}$ This unusual and elegant ring expansion strategy overcomes the current limitations encountered for the preparation of medium to large ring lactones, whether entropic or enthalpic by nature. 

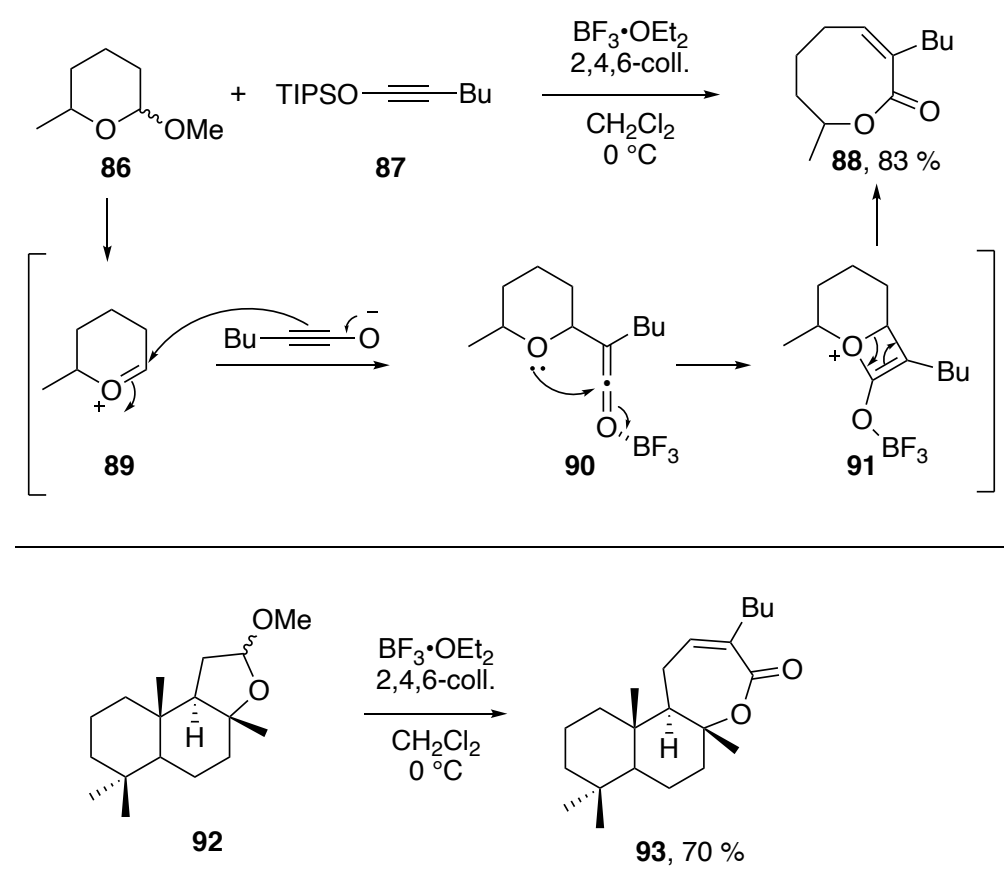

$<$ Scheme 24 near here $>$

Spiro-oxetenes have been proposed as intermediates in the synthesis of 3-substituted oxindoles $\mathbf{9 7} .{ }^{91}$ Indeed, copper(I)-catalyzed reaction of phenylacetylene $\mathbf{9 5}$, tosylazide $\mathbf{9 6}$ and isatin $\mathbf{9 4}$ led to a metal ynamidate 98 which could undergo a stepwise cyclization to spiro-oxetene intermediate 99. Ring opening of the latter finally afforded product $\mathbf{9 7}$ in excellent yield.

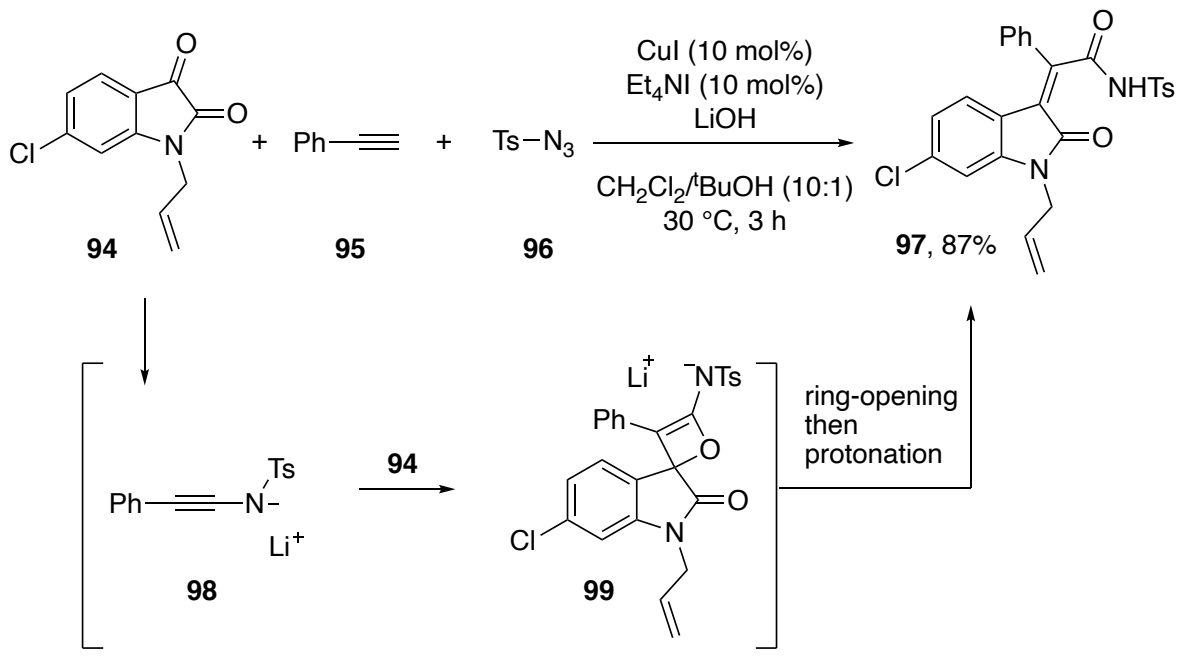

$<$ Scheme 25 near here>

The inherent strain of benzoxetenes has been judiciously exploited by Miyabe who reported the synthesis of ortho-disubstituted aromatics such as 101 from an aryne precursor 100, a formamide and diphenylzinc. ${ }^{92}$ Transient formation of benzoxetene 103, arising from reaction of benzyne 102 and DMF, undergoes a ring opening reaction to 104 which is immediately trapped in situ by diphenylzinc. 


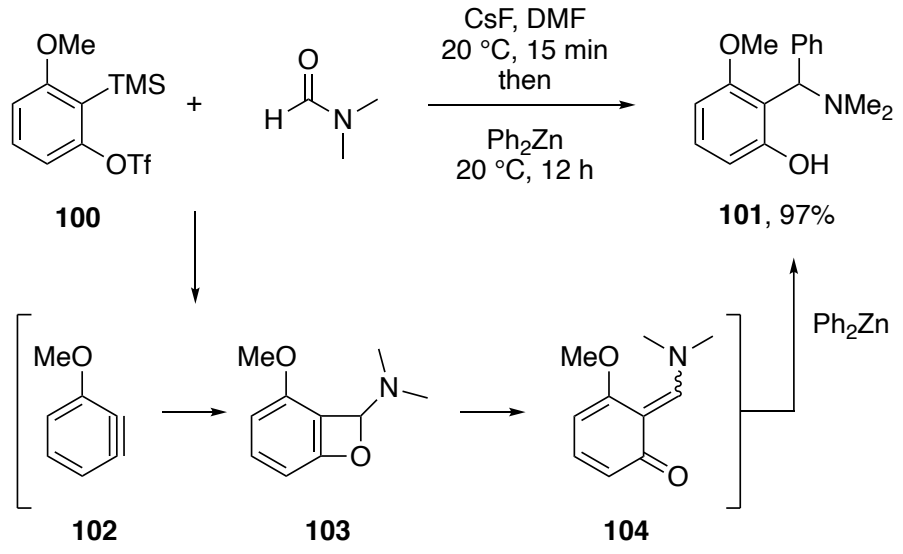

<Scheme 26 near here>

Diels-Alder cycloadditions of the intermediate ortho-quinone methide similar to 104 are also possible as shown by Yoshida. ${ }^{93}$ When the aryne precursor 105 is reacted with active methylene derivatives such as $\mathbf{1 0 6}$ in the presence of potassium fluoride, coumarins 107 are obtained in moderate to good yields.

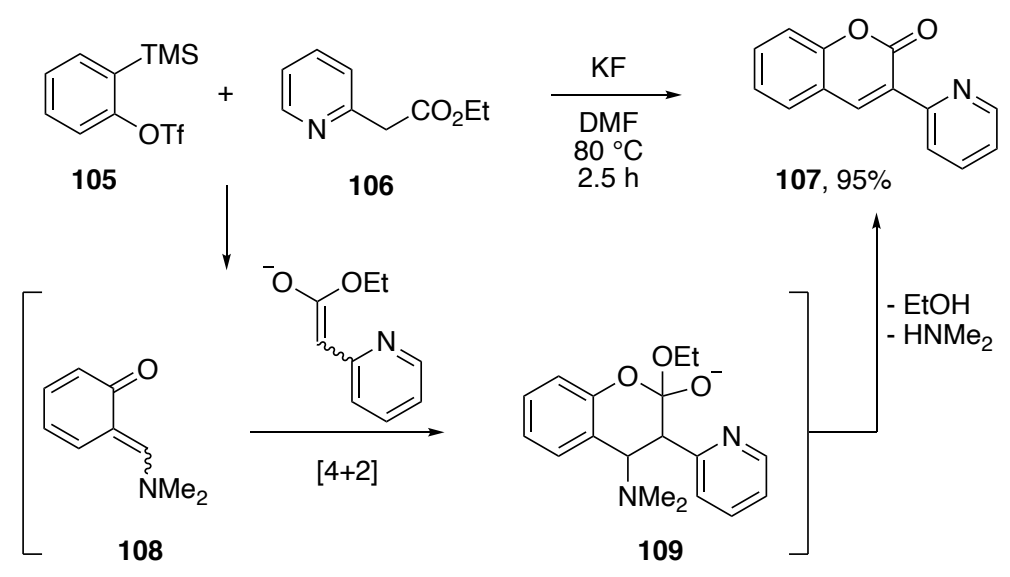

$<$ Scheme 27 near here>

Ortho-quinomethide 108 could also act as a nucleophile by delocalization of the lone pair of electrons of the nitrogen atom, and then react with an electrophile. Lu and Wang have demonstrated that benzoyl cyanide $\mathbf{1 1 0}$ was a relevant electrophile, leading to the formation of $\alpha$-amino carbonitriles 112 via an elegant three-component reaction. ${ }^{94}$<smiles>O=S(=O)(O)c1ccccc1O</smiles>

105<smiles>N#CC(=O)c1ccc(Br)cc1</smiles>

110

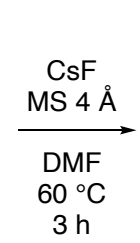

3 h<smiles>CC=C1C=CC=CC1C(=O)CCC</smiles>

108<smiles>CN=Cc1ccccc1OC(=O)C#N</smiles>

111<smiles>CC(N)C(Oc1ccccc1C(=O)OCc1ccccc1)c1ccc(Br)cc1</smiles>

<Scheme 28 near here>

\subsubsection{Cycloisomerisation of Oxetane-Containing Enynes}


$1 \alpha, 25$-Dihydroxyvitamin $D_{3}$, a seco-steroid having a key role in the regulation of calcium homeostasis, has been structurally edited to include a spiro-oxetane at C3 position..$^{95-97}$ The latter compound $\mathbf{1 1 5}$ is conveniently obtained via a Trost palladium-catalyzed cycloisomerisation ${ }^{98}$ of enyne $\mathbf{1 1 3}$ in the presence of vinyl bromide $\mathbf{1 1 4}$ in 66\% yield. It was shown that the introduction of a spiro-oxetane modified the conformation of $\mathbf{1 1 5}$ compared to the parent $1 \alpha, 25$-dihydroxyvitamin $D_{3}$, and thus favored the formation of ligand-vitamin $D$ receptor complex.

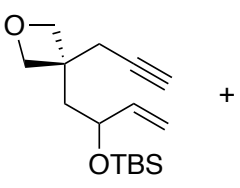

113

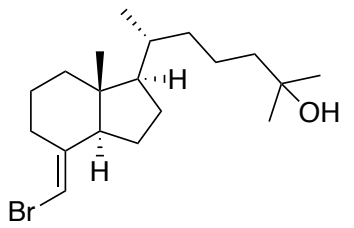

114

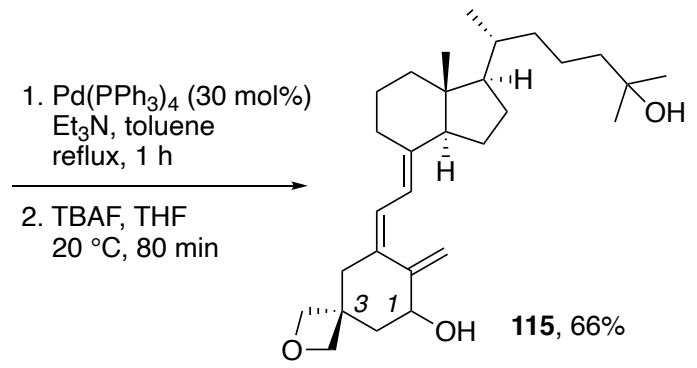

$<$ Scheme 29 near here>

\subsubsection{Reactivity of Substituents Attached to Ring Carbon Atoms}

\subsubsection{Exocyclic Alkenes}

1,3-Dipolar cycloaddition of azomethine ylide derived from 116 with exo-methylene oxetanes $\mathbf{4 0 b , c}$ leads to spiro-oxetanyl pyrrolidines $\mathbf{1 1 7} \mathbf{a}, \mathbf{b}$ in excellent yields. This copper(I)-catalyzed process relies on a planar-chiral ferrocene $\mathrm{P}, \mathrm{N}$-ligand that allows for a perfect control of exo-selectivity and high enantiomeric excesses (94-99\%). ${ }^{99}$ Silver-catalyzed processes were also reported. ${ }^{100}$

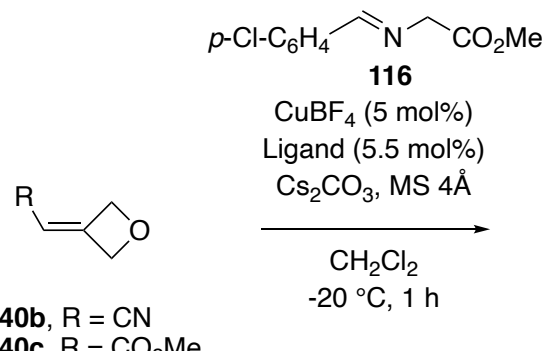

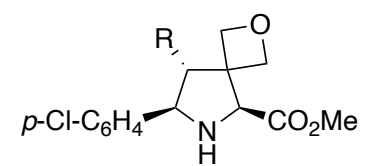

$117 a, 86 \%, d r>20: 1,99 \%$ ee $117 b, 91 \%$, dr $>20: 1,94 \%$ ee

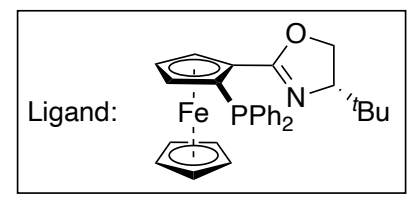

$40 \mathrm{c}, \mathrm{R}=\mathrm{CO}_{2} \mathrm{Me}$

$<$ Scheme 30 near here $>$

\subsubsection{Exocyclic Epoxides and Cyclopropanes}

2-Methyleneoxetane 118 could be converted into the corresponding epoxide 119 with good diastereoselectivity (8:1) and quantitative yield using anhydrous dimethyldioxirane (DMDO). Epoxideopening was best conducted with diisobutylaluminium hydride in dichloromethane, leading to $\mathbf{1 2 0}$ in $56 \%$ yield as a 3:1 mixture of diastereomers. ${ }^{101}$ 


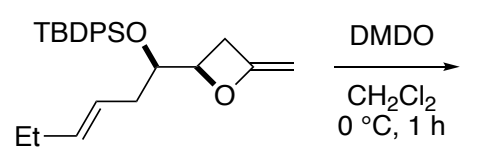

118

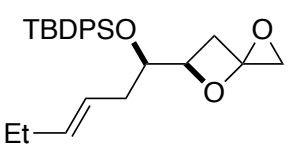

119, quant., $d r=8: 1$

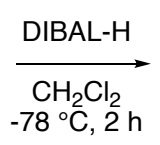

Et

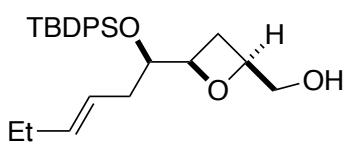

$120,56 \%, d r=3: 1$

\section{$<$ Scheme 31 near here>}

Spirocyclopropyl oxetanes $\mathbf{1 2 1}$ were reported to rearrange to 3-methylenetetrahydrofurans $\mathbf{1 2 2}$ upon treatment with a catalytic amount of Zeise's dimer and 20 mol\% of tricyclohexylphosphine in dichloromethane at $45{ }^{\circ} \mathrm{C} .{ }^{102}$ The mechanism of this new platinum-catalyzed rearrangement was extensively studied (including with ${ }^{13} \mathrm{C}$ NMR-labeling) and it was found that oxidative addition of the substrate to platinum(II) was taking place at the least substituted carbon-carbon bond of the spirocyclopropyl unit.

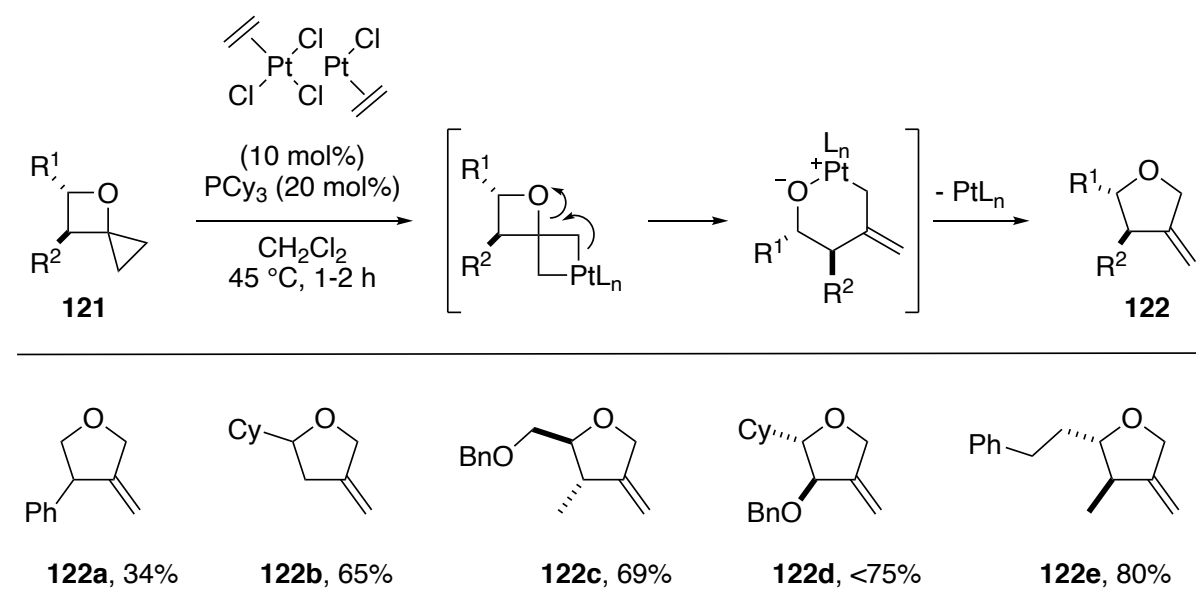

$<$ Scheme 32 near here>

Spirocyclic oxetanes 123, obtained by photocycloaddition of $\mathrm{N}$-acylisatins and bicyclopropylidene, could be ring-opened by an excess of acid, such as hydrochloric or hydrobromic acid in acetonitrile at room temperature, yielding spirocyclopropyl butenolide $\mathbf{1 2 4}$ in good yield. ${ }^{103}$ On the other hand, $\gamma$ butyrolactones $\mathbf{1 2 5}$ possessing the two spirocyclopropane units were obtained upon action of hydroiodic acid and iodine. 


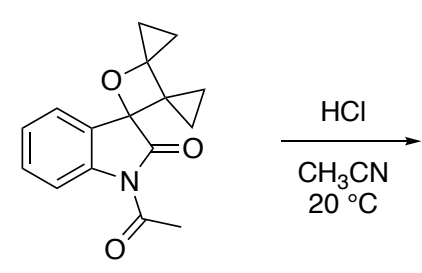

123

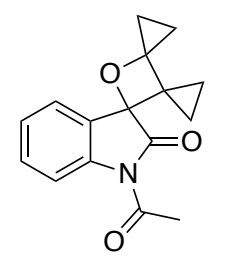

123<smiles>CC(=O)Nc1ccccc1C1=C(CCCl)C2(CC2)OC1=O</smiles>

$124,80 \%$

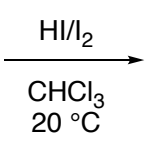<smiles>CC(=O)Nc1ccccc1C1CCC2(CC2)OC1=O</smiles>

125, $84 \%$

$<$ Scheme 33 near here>

2.06.7.3 Reactivity of Exocyclic Radicals

Mono-debromination of spirooxetane $\mathbf{1 2 6}$ was performed with tributyltin hydride in toluene at room temperature. A single diastereomer $\mathbf{1 2 7}$ was obtained, although the yield was only $21 \% .{ }^{104}$

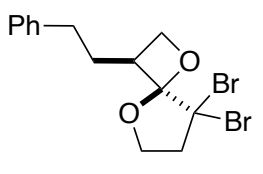

126

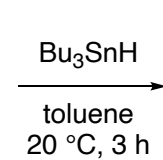

$20{ }^{\circ} \mathrm{C}, 3 \mathrm{~h}$

<Scheme 34 near here>

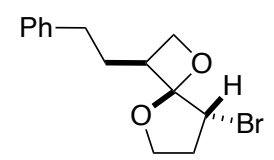

$127,21 \%$

\subsubsection{Reactivity of Substituents Attached to Ring Heteroatoms}

No examples of this class of compounds have been found in the literature in the period covered.

\subsubsection{Ring Synthesis Classified by the Number of Ring Atoms}

\subsubsection{Intermolecular [2+2] Cycloaddition Reactions}

Paternò-Büchi [2+2] photocycloaddition ${ }^{77,105}$ is one of the most direct route to oxetanes and this well-established transformation can be transposed to flow conditions, as demonstrated in the synthesis of the cytotoxic lactone (+)-goniofufurone 132, isolated from Goniothalamus trees. ${ }^{106}$ Thanks to fluorinated ethylene polymer (FEP) continuous flow reactors in conjunction with a mercury medium-pressure lamp (400 W), the [2+2] reaction of $\mathbf{1 2 8}$ with benzaldehyde could be upscaled to deliver $42 \mathrm{~g}$ of photocycloadducts $\mathbf{1 2 9}$ and $\mathbf{1 3 0}$ (97\% combined yield). 


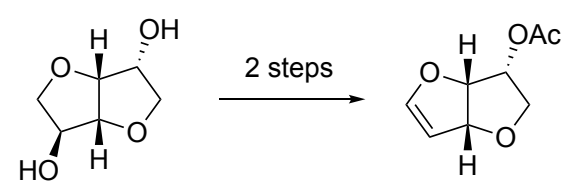

D-isosorbide
$128,78 \%$

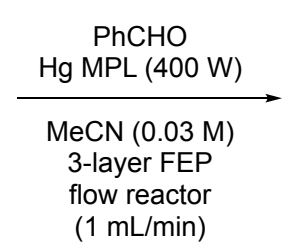

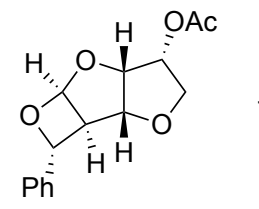

129

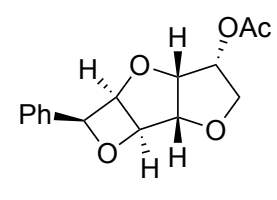

130

$129 / 130=1: 2,97 \%$

$42 \mathrm{~g}$ in a single $83 \mathrm{~h}$ run
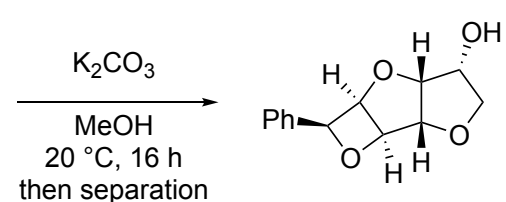

131

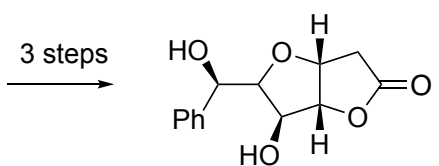

(+)-goniofufurone 132, $22 \%$

\section{<Scheme 35 near here>}

The Paternò-Büchi [2+2] photocycloaddition of oxindoles has also been reported using a visible-light microfluidic photoreactor. ${ }^{107}$ Optimization of photocycloadditions under flow conditions can also be conducted in an automatic fashion using self-optimizing algorithms. Rueping demonstrated that the [2+2] photocyclization of benzophenone and furan in a capillary-type continuous photo-flow reactor could indeed be optimized without human intervention. ${ }^{108}$

Paternò-Büchi [2+2] photocycloaddition proceeds via direct carbonyl excitation or photosensitization followed by alkene interception as in Scheme 35. In this regard, alkyl substituted ketones are not the most reactive partners and require more energetic irradiation and specialized glassware. However, it was demonstrated in 2019 by Schmidt that a copper(I)-norbornene complex was able to catalyze the [2+2] carbonyl-olefin photocycloaddition with a broad range of alkyl ketones. ${ }^{109} \mathrm{~A}$ relevant example is described in Scheme 36 with the reaction of ketone $\mathbf{1 3 3}$ and norbornene 134. In the presence of 10 mol\% of copper(I) tri(1H-pyrazol-1-yl)hydroborate $(\mathrm{TpCu})$ and under irradiation with a $100 \mathrm{~W}$ mercury lamp, a good yield of adduct $\mathbf{1 3 5}$ is obtained. The reaction pathway is mechanistically distinct from classical Paternò-Büchi reactions and relies on the excitation of an in situ formed $\mathrm{TpCu}$ (Norb) complex.

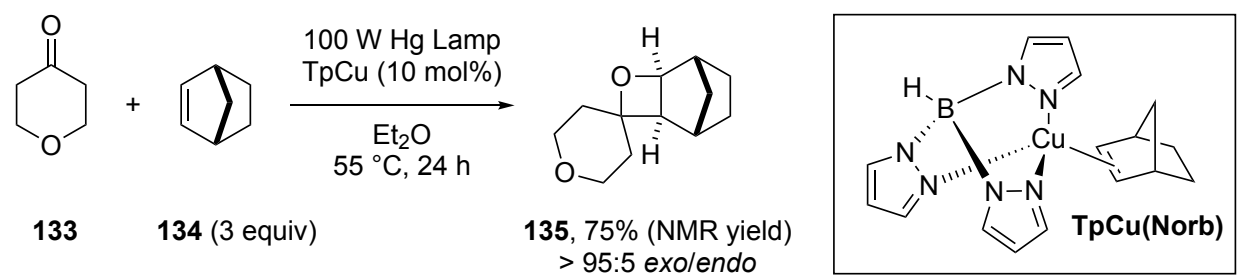

$<$ Scheme 36 near here>

Unprecedented angular tricyclic 4:4:4 oxetane-containing compounds were obtained by Aitken through a triple photochemical process, starting from 4-substituted cyclopentenones 136 and alkenes. ${ }^{110}$ Under irradiation at $300 \mathrm{~nm}$ for $40 \mathrm{~h}$ in acetonitrile, 12 different angular tricyclic oxetanes were obtained with moderated to good diastereoselectivities. A plausible mechanism calls for an initial [2+2] photocycloaddition followed by a Norrish-1/ $\gamma-\mathrm{H}$ transfer. A final intramolecular PaternòBüchi reaction would then deliver 137. 


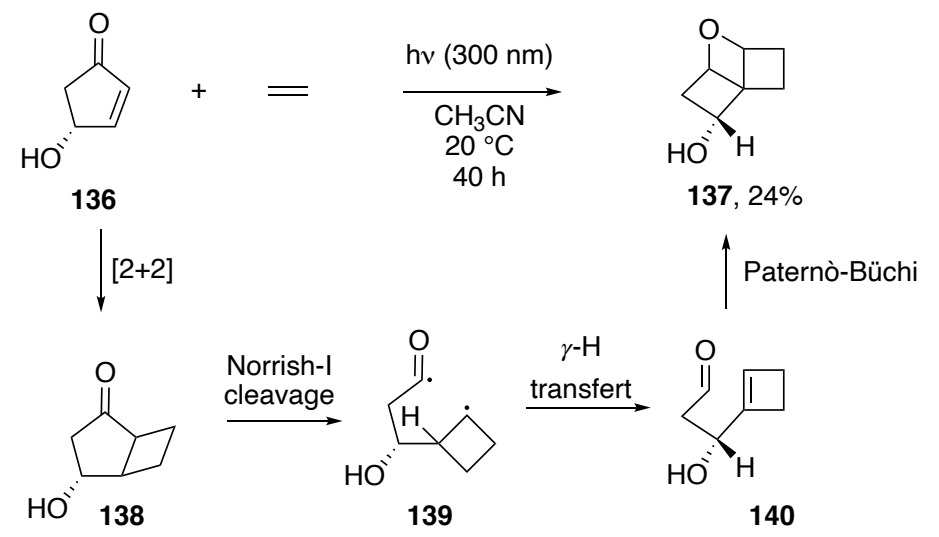

$<$ Scheme 37 near here>

Photocycloadditions of isoquinoline-1,3,4-trione with 5-methoxyoxazoles were reported by Zhang. Fused oxetanes were obtained in very good yields and could be rearranged to spiroisoquinolineoxazolines under acidic conditions. ${ }^{111}$

\subsubsection{Intramolecular Paternò-Büchi Cycloadditions}

Transposed Paternò-Büchi [2+2] photocycloadditions of atropoisomeric enamides 141 have been reported by Sunoj and Sivaguru, during which a switch in excited states from $n-\pi^{*}$ of the carbonyl group to $\pi-\pi^{*}$ of the alkene occurs. ${ }^{112}$ After cycloaddition under sensitized conditions, chirally enriched oxetanes 142 were obtained.

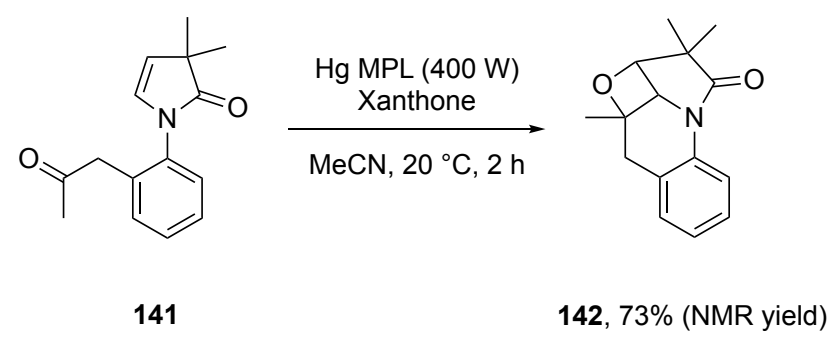

$<$ Scheme 38 near here>

\subsubsection{Norrish II (Biradical) Cyclization}

Photoreaction of 2-isopropoxy naphthoquinone $\mathbf{1 4 3}$ in the presence of bicyclopropylydene leads to the expected cyclobutane $\mathbf{1 4 4}$ after 3 hours. However, upon extended irradiation time, a $\gamma$-hydrogen abstraction occurs from the triplet state of alkoxyketone $\mathbf{1 4 4}$ leading to the fused-oxetane $\mathbf{1 4 5}$ in $54 \%$ yield. ${ }^{113}$ 
<smiles>CC(C)OC1=CC(=O)c2ccccc2C1=O</smiles>

143

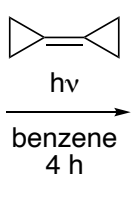

h

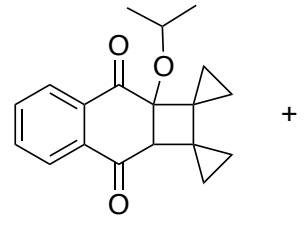

$144,6 \%$

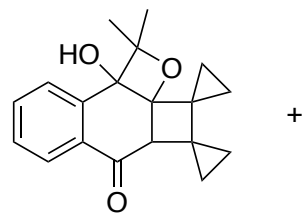

$145,54 \%$

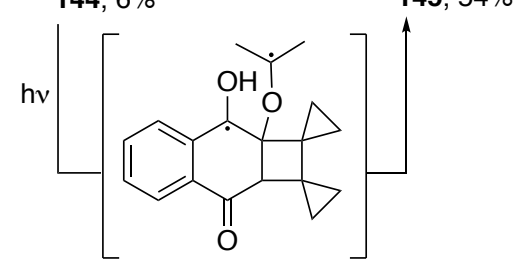

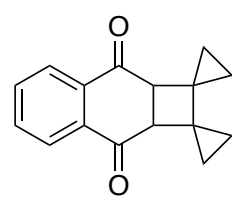

$146,25 \%$

$<$ Scheme 39 near here $>$

\subsubsection{Cycloadditions of Ketene Equivalents}

Bode reported in 2009 that chiral triazolium-derived NHCs were able to catalyze the formation of fused $\beta$-lactones with an excellent enantioselectivity via the intermolecular reaction of an enal 147 and an $\alpha$-hydroxyenone $148 .{ }^{114}$ Quite surprisingly, the use of chiral imidazolium-derived NHC led to a different fused lactone, also with excellent enantioselectivity. A detailed mechanistic discussion proposes that the different reactivities of the intermediate acylazolium species involved in the lactone-forming step, such as $\mathbf{1 5 3}$ derived from catalyst 150, might be responsible for this outcome.

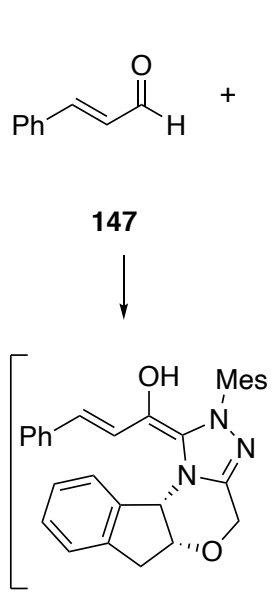

151

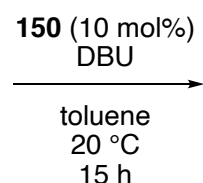

148

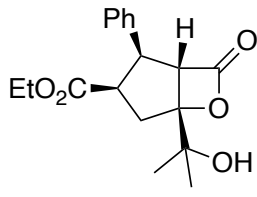

$149,65 \%, 99 \%$ ee

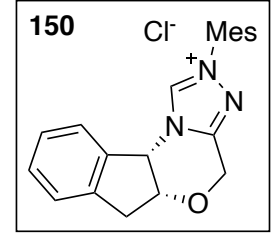

$<$ Scheme 40 near here $>$

Related NHC-catalyzed synthesis of fused $\beta$-lactones from enals and 2-enoylpyridines ${ }^{115}$ or oxindolyl $\beta, \gamma$-unsaturated $\alpha$-ketoesters ${ }^{116}$ were reported. Scheidt reported the first NHC-catalyzed dynamic kinetic resolution (DKR) of $\beta$-ketoesters 154 substituted in the $\alpha$-position, leading to fused $\beta$ lactones. ${ }^{117,118}$ When applied to electron-rich ketones (such as 156), this DKR strategy is followed by a spontaneous decarboxylation process that afforded cyclopentene 158. ${ }^{119}$ This concerted asynchronous retro-[2+2] reaction was studied using quantum mechanical computations and it was found that the anti-selective process was favored based on steric interactions between the carboxylate and the $\alpha$-substituent in the syn-transition state. 

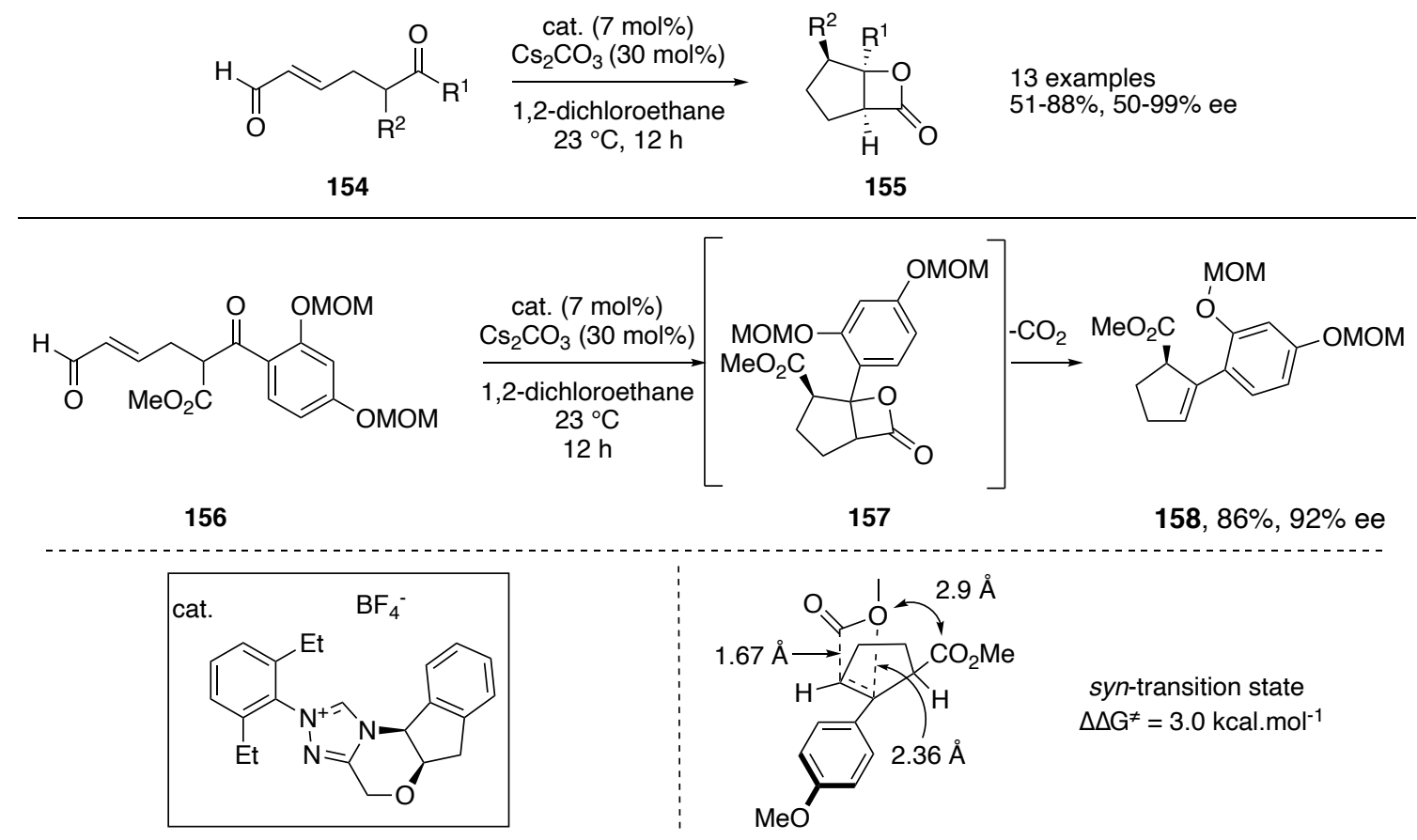

$<$ Scheme 41 near here>

Chiral NHCs developed by Lupton were shown to catalyze the formation of $\beta$-lactones fused to cyclopentanes 161, starting from $\alpha, \beta$-unsaturated acyl fluorides 159 and donor-acceptor cyclopropanes $160 .{ }^{120,121}$ The process is general and $\mathrm{R}^{1}$ could be an aryl, alkyl, alkenyl group whereas $\mathrm{R}^{2}$ could be alkyl or cycloalkyl. Good yields and enantioselectivities up to $97 \%$ were obtained for compounds 161. Mechanistically, two pathways were proposed based on the different modes of addition of enolate 162 onto intermediate 163. 


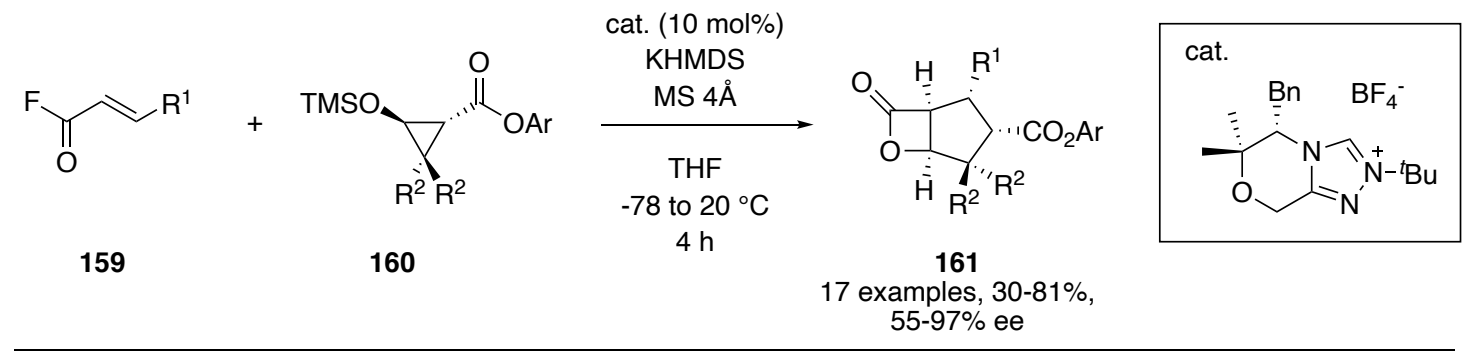

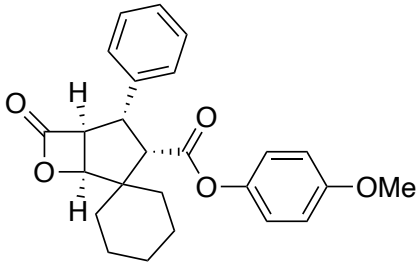

161a, $72 \%, 90 \%$ ee

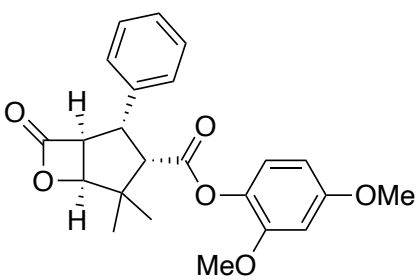

$161 \mathrm{~d}, 70 \%, 83 \%$ ee

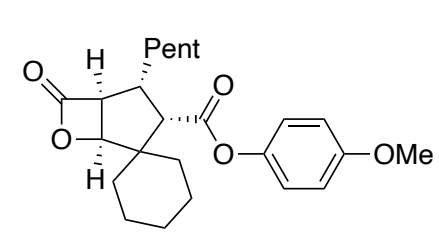

161b, $80 \%, 93 \%$ ee

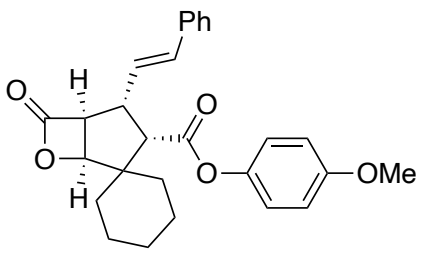

161c, $51 \%, 87 \%$ ee

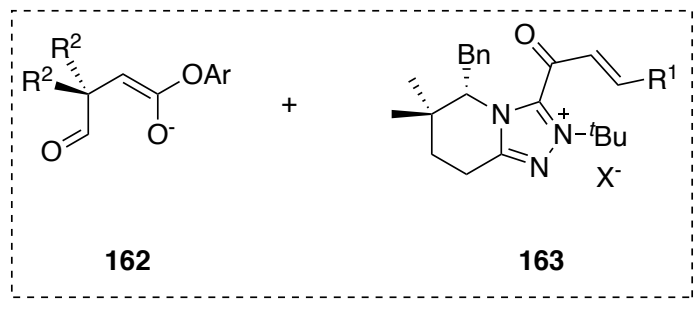

<Scheme 42 near here $>$

Besides donor-acceptor cyclopropanes, $\beta$-diketones, $\beta$-ketoesters and malonates (such as compound 165) proved to be competent partners in oxidative carbene catalysis, leading to fused $\beta$-lactones 166. An interesting cooperative Lewis acid effect was observed, yields and enantioselectivities being optimal in the presence of 50 mol\% of lithium chloride. ${ }^{122}$

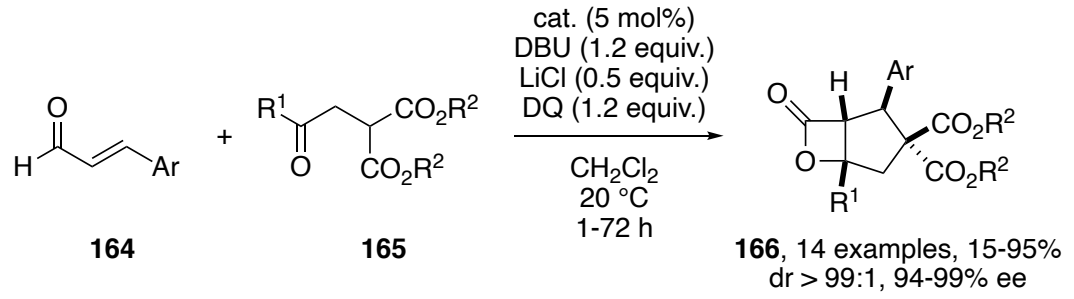

$<$ Scheme 43 near here>

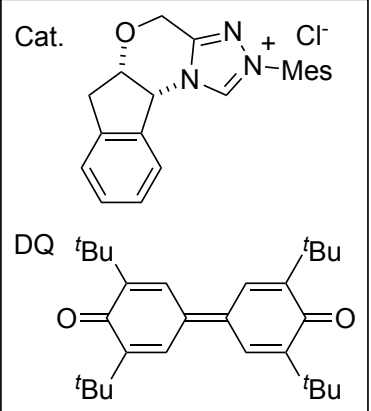

Chi reported that bicyclic pyrrolidine-fused $\beta$-lactones 169 could be obtained with excellent yields and stereoselectivities from aldehydes 147 and amino esters 167 via a chiral NHC-catalyzed reaction that created the desired $\beta$-lactone as well as a new carbon-nitrogen bond in $\beta$-position relative to the carbonyl. ${ }^{79}$ The proposed mechanism relies on the generation of an acyl-azolium intermediate $\mathbf{1 7 0}$ that undergoes an intermolecular Michael addition of the sulfonamide $\mathbf{1 6 7}$ followed by aldol/ $\beta$ lactonization to 169. 


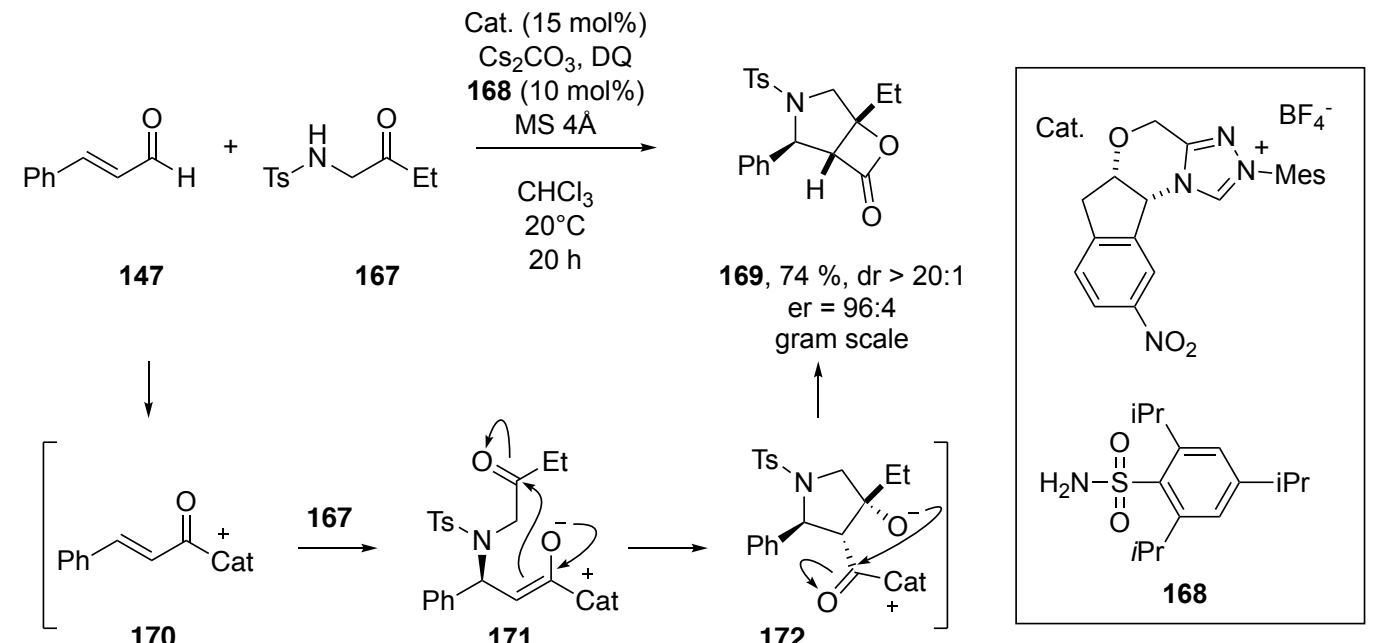

$<$ Scheme 44 near here>

$\alpha, \beta$-Unsaturated acylammonium intermediates are also competent partners as shown by Romo in $2013^{123}$ who proposed a multicomponent organocascade reaction coined Nucleophile-Catalyzed Michael-Aldol- $\beta$-Lactonization (NCMAL), which led to the synthesis of $\beta$-lactone $\mathbf{1 7 4}$ in excellent yields and enantioselectivities.

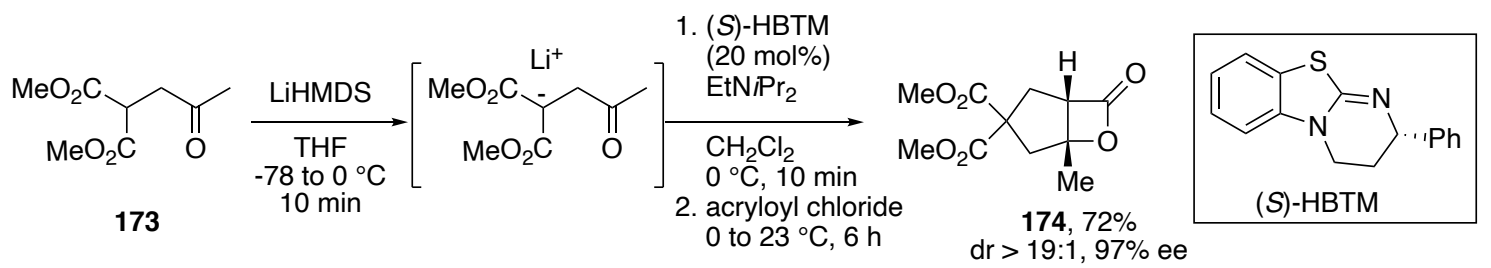

<Scheme 45 near here>

\subsubsection{Intramolecular Nucleophilic Displacements}

Brown reported a novel palladium-catalyzed deallylative cyclization of $\mathbf{1 7 5}$ to synthesize $\beta$-lactone rings 176, an elegant strategy that was applied to the total synthesis of $( \pm)$-vibralactone, a natural product isolated from the culture of Basidiomycete Borestereum vibrans. ${ }^{124}$ Palladium-catalyzed deprotection of $\beta$-mesyloxy ester $\mathbf{1 7 5}$ led to the desired $\beta$-lactone $\mathbf{1 7 6}$ in only 2 minutes in $\mathbf{9 5 \%}$ yield. Although this reaction does not strictly fall into the area covered by this chapter focused on fused $\beta$ lactones, it would be interesting to study the formation of bicyclic $\beta$-lactones via this novel type of intramolecular cyclization.
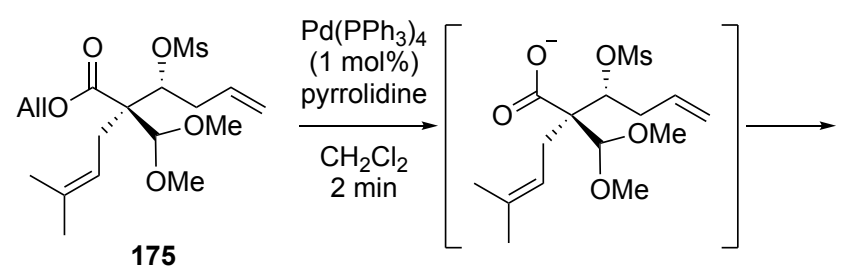

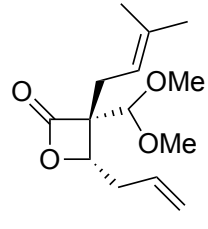

$176,95 \%$

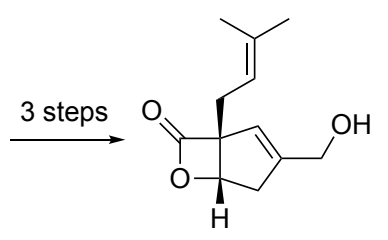

(士)-vibralactone, $59 \%$

$<$ Scheme 46 near here> 
Bull reported the two-step preparation of diversely substituted oxetanes $\mathbf{1 8 0}$ from functionalized diazo-compounds $\mathbf{1 7 7}$ by rhodium-catalyzed $\mathrm{O}-\mathrm{H}$ insertion followed by a base-mediated cyclization of intermediate 179. Several fused [3.2.0] ring systems $\mathbf{1 8 0}$ were obtained, in addition to an oxabicyclo[4.2.0]octane, in excellent yields. ${ }^{125,126}$

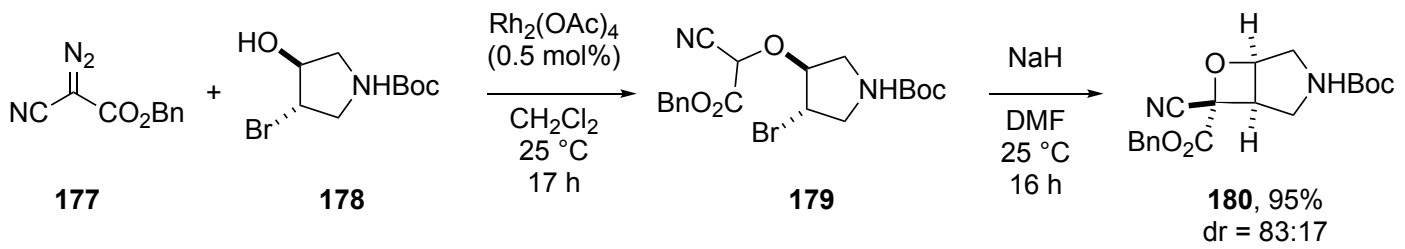

$<$ Scheme 47 near here $>$

Benzoxetes 182 were efficiently prepared by Qin through a sulfuryl fluoride-mediated conversion of 2-hydroxy acetophenones 181 in the presence of potassium carbonate in DMSO at $90^{\circ} \mathrm{C} . .^{127}$

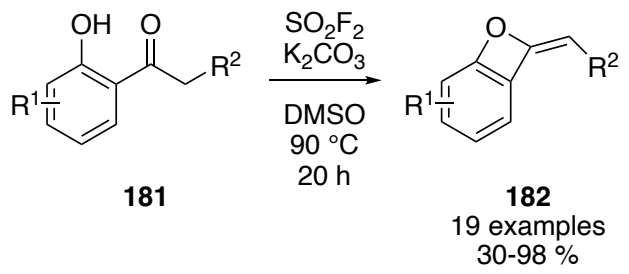

$<$ Scheme 48 near here>

Researchers at Merck reported an optimized synthetic route towards spiro-oxetane containing piperidines and pyrrolidines via a simple intramolecular $\mathrm{S}_{\mathrm{N}} 2$-type displacement of a primary tosylate. ${ }^{128,129}$ The latter is prepared in situ from diol $\mathbf{1 8 3}$ using $n$-butyllithium and tosyl chloride; the addition of a second equivalent of $n$-butyllithium then delivered the desired spiro-oxetane piperidine 185 in $66 \%$ yield on a $37 \mathrm{~g}$ scale. Similar strategy led to compounds 186 and 187 from ethyl nipecotate and methyl 1-benzylpyrrolidine-3-carboxylate (respectively).

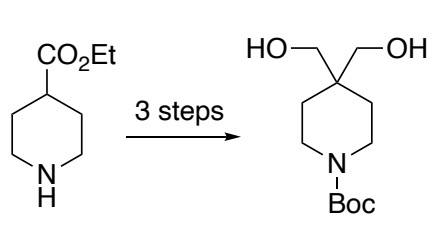

183

$184,39-52 \%$

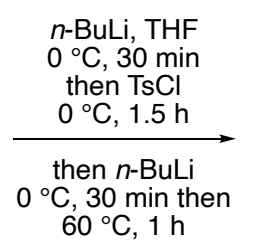

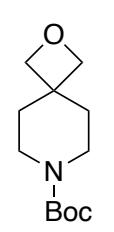

$185,66 \%$

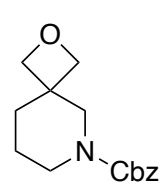

186, $15 \%$ (from ethyl nipecotate)

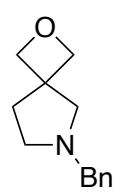

$187,33 \%$ (from methyl 1benzylpyrrolidine-3carboxylate)

<Scheme 49 near here>

\subsubsection{Dehydration of Hydroxy Acids}

Bis(2-oxo-3-oxazolidinyl)phosphinic chloride (BOPCl) proved to be a reliable and efficient reagent for the synthesis of fused $\beta$-lactones within densely functionalized scaffolds. It has been applied to the 
ring closure of numerous $\beta$-hydroxyacids in the context of total synthesis of natural products, such as $(+)$-lactacystin, ${ }^{130}$ a rocaglate-derived $\beta$-lactone, ${ }^{131}$ (-)-7-methylomuralide, ${ }^{132}$ (-)-omuralide, ${ }^{133}$ or salinosporamide $A^{134-136}$ to cite only a few. As an example, Burton reported a high-yielding sequence from $\beta$-hydroxyester 188 to salinosporamide $A$ in 3 steps (61\% overall), using $\mathrm{BOPCl}$ as the key coupling agent. ${ }^{137}$ As noted in previous versions of this chapter, this reaction leads to the fused $\beta$ lactone only and no traces of spiro- $\beta$-lactone (arising from the cyclization of the exocyclic secondary alcohol) were detected.<smiles>O=C1NC(O)(C2(O)C=CCCC2)C(O)C1CCO</smiles>

188

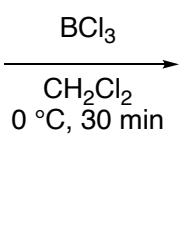

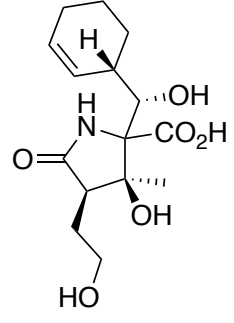

189
1. $\mathrm{BOPCl}(1.7$ equiv.) $\mathrm{CH}_{2} \mathrm{Cl}_{2}$ /pyridine $(2: 1)$ $20^{\circ} \mathrm{C}, 3 \mathrm{~h}$

2. $\mathrm{Ph}_{3} \mathrm{PCl}_{2}$ (2 equiv.) $\mathrm{CH}_{3} \mathrm{CN} /$ pyridine $(1: 1)$ $20^{\circ} \mathrm{C}, 2 \mathrm{~h}$

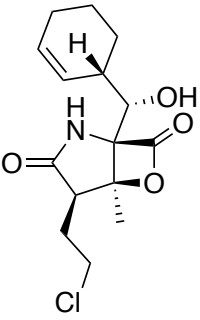

salinosporamide A (61\% over 3 steps)

$<$ Scheme 50 near here $>$

\subsubsection{Electrophilic Cyclizations onto Alkenes}

Bromolactonization of $\beta, \gamma$-unsaturated carboxylic acid is a reliable and simple method to synthesize $\beta$-lactones, especially on large scale. Millenium Pharmaceuticals has reported a practical synthesis of Pevonedistat, a NEDD8-activating enzyme (NAE) inhibitor using the bromolactonization of 190 to bicyclic intermediate 191 as one of the key steps. ${ }^{138}$

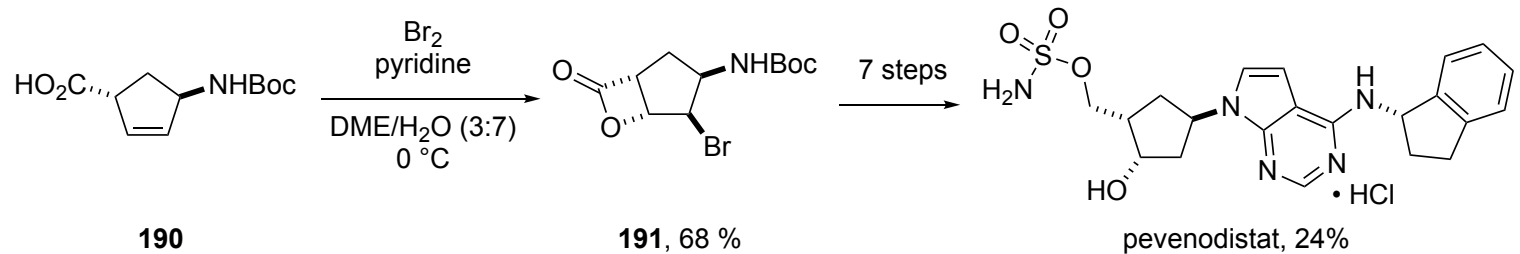

$<$ Scheme 51 near here $>$

Acetal-substituted spiro-oxetanes 193 having a 1,5-dioxaspiro[3.4]octane scaffold were prepared through a bromocation-induced cyclization of bis-homopropargylalcohols 192 with pyridinium tribromide. ${ }^{104}$

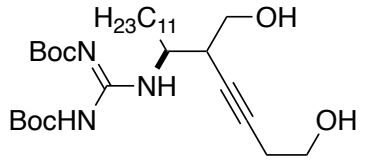

192

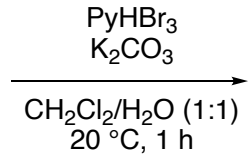

$20{ }^{\circ} \mathrm{C}, 1 \mathrm{~h}$

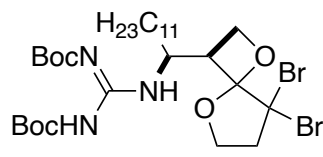

193, $27 \%$

$<$ Scheme 52 near here $>$ 


\subsubsection{Cationic Cyclizations}

Oxidative dearomatization of phenols is an interesting class of reactions that is relevant to the formation of fused oxetane, as shown for the first time by Li in 2014. ${ }^{139}$ Treatment of substituted phenol 194 by $\mathrm{Phl}(\mathrm{OAc})_{2}$ in aqueous acetonitrile led to the strained oxetane 195 in moderate yield.

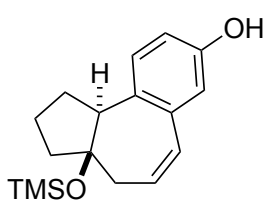

194

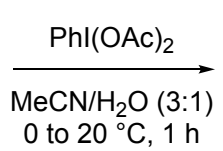

0 to $20^{\circ} \mathrm{C}, 1 \mathrm{~h}$

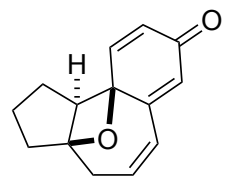

195, $42 \%$

$<$ Scheme 53 near here>

\subsubsection{Intramolecular C-H Insertion}

Moody reported a straightforward preparation of spiro- $\beta$-lactones 197 based on the selective 1,4-C$\mathrm{H}$ insertion reactions of rhodium carbenes derived from $\alpha$-diazoesters $196 .{ }^{140}$ The latter could be generated in flow or in classical batch chemistry. The obtained $\beta$-lactones could then be reduced to oxetanes using a two-steps protocol discussed in Section 2.06.6.3.

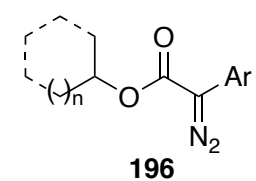

196

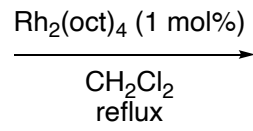

(H) 197

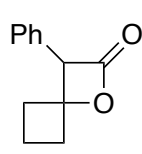

$197 a, 61 \%$

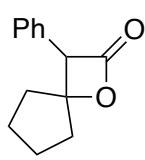

197b, 32\%

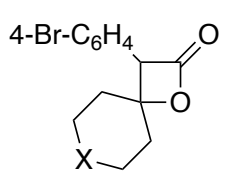

197c, $\mathrm{X}=\mathrm{CH}_{2}, 70 \%$ 197d, $X=$ NBoc, $58 \%$<smiles></smiles><smiles>O=C(O)CCCCCC1C(=O)OC12CCC1(CC2)OCCO1</smiles>

$197 \mathrm{e}, 68 \%$

$<$ Scheme 54 near here $>$

Metalloporphyrin catalysts are also efficient for $\mathrm{C}-\mathrm{H}$ functionalization reactions, as shown by $\mathrm{Che}$. For example, the methylated iridium(III) porphyrin complex $[\mathrm{Ir}(\mathrm{TTP}) \mathrm{Me}(\mathrm{L})]\left(\mathrm{H}_{2} \mathrm{TTP}=\right.$ meso-tetrakis $(p$ tolyl)porphyrin; $\mathrm{L}=\mathrm{H}_{2} \mathrm{O}$ or solvent) was able to catalyze the formation of spiro- $\beta$-lactone $\mathbf{1 9 7 f}$ from $\alpha$-diazoester $196 \mathrm{f}$ at room temperature in only $1 \mathrm{~h} .{ }^{141}$

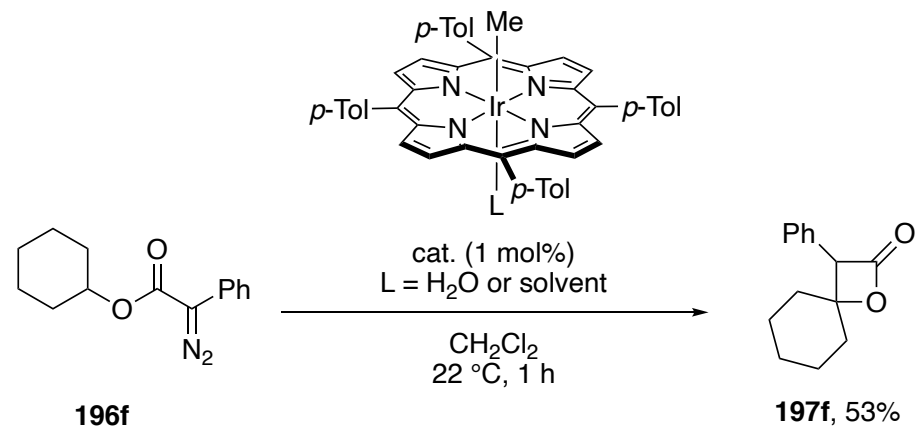

$<$ Scheme 55 near here $>$ 


\subsubsection{Ring Synthesis by Transformation of Another Ring}

\subsubsection{Rearrangement of Epoxides}

Highly strained fused oxetane, such as the one embedded in merrilactone A 199, a natural product isolated from the pericarps of Illicium merrillianum in 2000, has been prepared by the Fukuyama procedure ${ }^{142}$ involving a stereoselective epoxidation of the trisubstituted alkene of $\mathbf{1 9 8}$ followed by a homo-Payne rearrangement. ${ }^{143,144}$ This classical reaction has been used in several syntheses of the neurotrophic active natural product. ${ }^{145}$

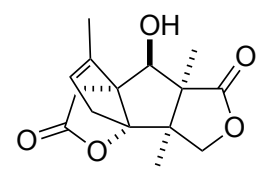

198

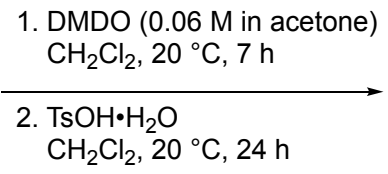

$\mathrm{CH}_{2} \mathrm{Cl}_{2}, 20{ }^{\circ} \mathrm{C}, 24 \mathrm{~h}$

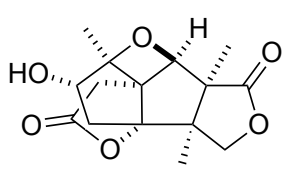

199, ( \pm )-merrilactone A, $74 \%$

$<$ Scheme 56 near here>

\subsubsection{Carbonylation of Epoxides}

Enantioenriched fused $\beta$-lactones 201 can be prepared via an asymmetric ringexpansion/carbonylation reaction of meso-epoxides 200. Combination of catalytic amounts of a chiral chromium(III) complex and dicobalt octacarbonyl proved to be optimal to promote this important class of reactions. ${ }^{146}$

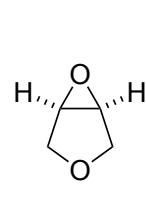

200

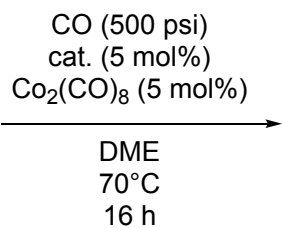

$16 \mathrm{~h}$

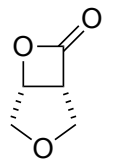

$201,93 \%, 56 \%$ ee

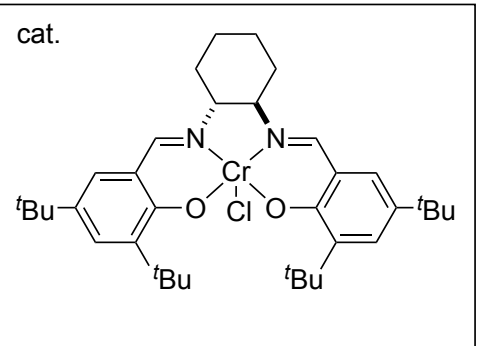

$<$ Scheme 57 near here>

Spiro-epoxides such as $\mathbf{2 0 2 a}$ and $\mathbf{2 0 2}$ b were shown to react with high regioselectivity under carbon monoxide atmosphere (900 psi) in diisopropylether at room temperature in presence of an octaethylporphyrin catalyst. Mechanistic investigations demonstrated that the rate-limiting step of the reaction was the epoxide ring-opening, leading to $203 \mathbf{a}, \mathbf{b}$ as the final products. ${ }^{147}$ 

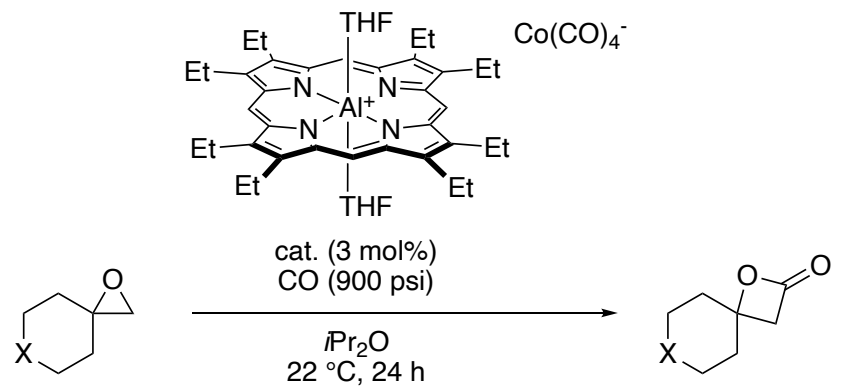

202a, $\mathrm{X}=\mathrm{CH}_{2}$ 202b, $X=$ NBOC

203a, 67\%

203b, $91 \%$

$<$ Scheme 58 near here>

\subsubsection{Rearrangement of Diazoketones}

A rare example of Wolff rearrangement of a rhodium carbene was reported by Chiu in 2017, leading to the fused $\beta$-lactone $\mathbf{2 0 5}$ in $\mathbf{3 9 \%}$ yield alongside two other products. It was hypothesized that the conformation of the [4.4.0] bicyclic diazoketone 204 could be responsible for this specific outcome. $^{148}$

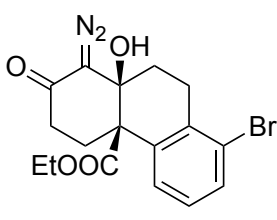

204

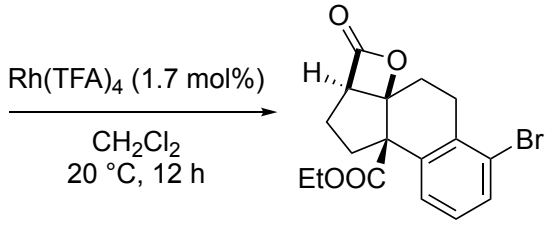

205, $39 \%$

$<$ Scheme 59 near here>

\subsubsection{Important Compounds and Applications}

Oxetanes are found in more than 600 naturally occurring structures produced by microorganisms or plants. ${ }^{149}$

\subsubsection{1 (-)-Stemoamine}

$\beta$-Lactones can be transient intermediates en route to cyclopentenones via a tandem sequence of ynolate addition onto a ketone followed by intramolecular condensation onto an ester and decarboxylation. Such a sequence was used by Shindo in 2018 in the total synthesis of (-)stemoamine, an alkaloid isolated from the root of Stemona japonica Miq. that has been used in traditional Chinese medicine. ${ }^{150}$ Addition of ynolate $\mathbf{2 0 8}$ (generated from 207 and ${ }^{t} \mathrm{BuLi}$ ) to ketone 206 led to the formation of 211, that can undergo silica gel-assisted decarboxylation in refluxing benzene. ${ }^{151}$ The very efficient sequence forms the A-ring of (-)-stemoamine. 


$$
{ }_{\mathrm{CO}_{2} \mathrm{Ph}}^{\mathrm{Br}}
$$

206

${ }^{\text {tBuLi, THF }}$

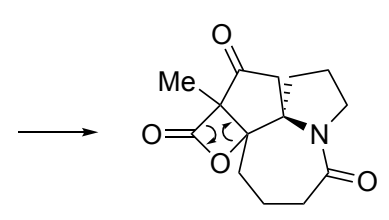

211

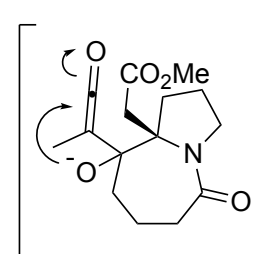

209

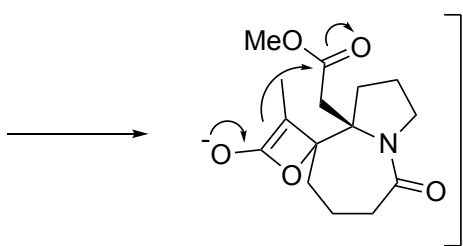

210

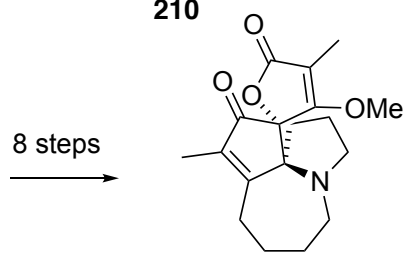

(-)-Stemoamine, $18 \%$

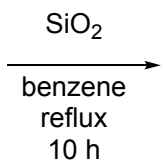

$10 \mathrm{~h}$

$<$ Scheme 60 near here>

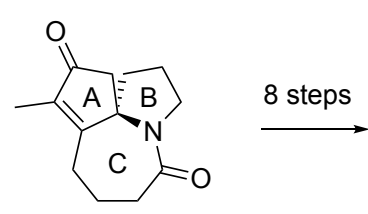

$212,88 \%$

\subsubsection{2 ent-Dichrocephone B}

Fully substituted oxetanes are found in natural products such as dichrocephone B 217. In 2018, the total synthesis and structure revision of this compound was reported by Christmann and Tantillo, featuring a Lewis acid-mediated cyclization of ent-dichrocephone A 216 into ent-dichrocephone B $\mathbf{2 1 7}$ in $88 \%$ yield. A low yield (12\%) was obtained for the acid-mediated cyclization of $\mathbf{2 1 5} .{ }^{152}$

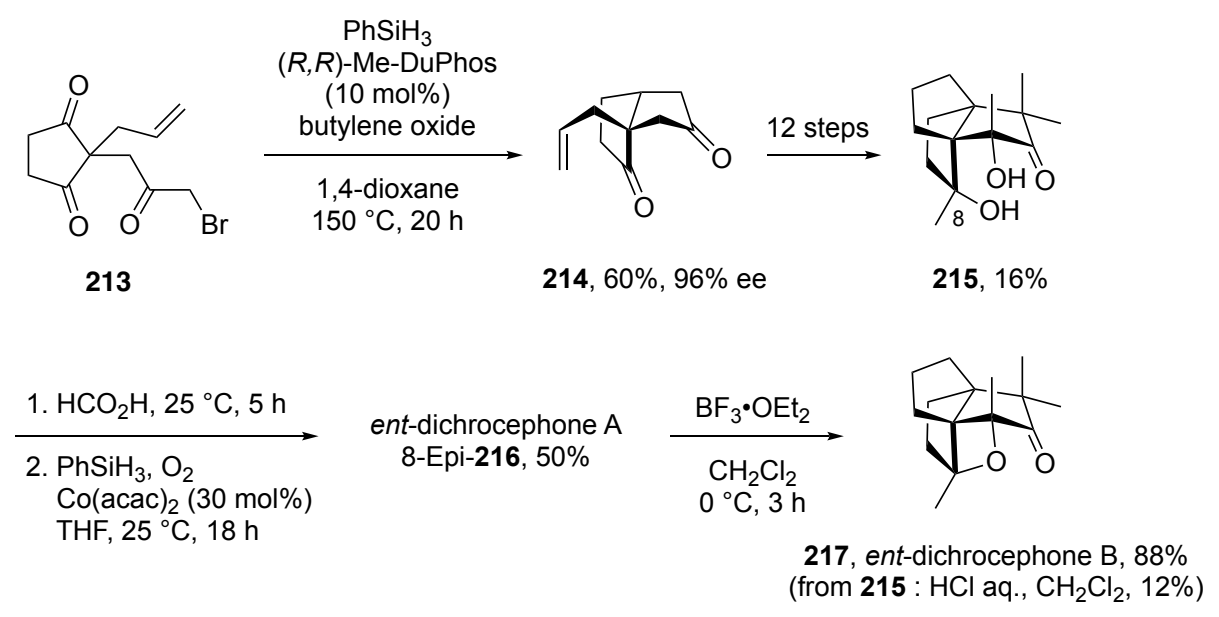

$<$ Scheme 61 near here>

\subsubsection{3 ( \pm )-Spongiolactone}

Fused $\beta$-lactones are obtained through an elegant procedure reported by Romo starting from aldehydic acids. ${ }^{153,154}$ Intramolecular Nucleophile-Catalyzed Aldol Lactonization (NCAL) reactions delivers $\beta$-lactones with excellent functional group tolerance; chiral amines were also shown to induce high enantioselectivity to the process ${ }^{153}$ and applications to the total synthesis of natural products were disclosed, as in the ( \pm )-spongiolactone case (Scheme 60 ). Extension to the dynamic kinetic resolution of keto-acids was also reported. ${ }^{155}$ 
<smiles>O=C1CCCC(=O)C1</smiles><smiles>CC(C)CC(=O)OC[C@H]1CC[C@@H](C2(C)CCCC(C)(C)C2)[C@H](CCC(=O)O)C1</smiles>

219, $5 \%$

218

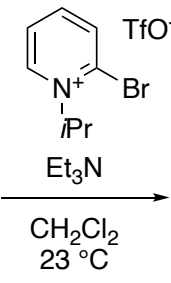<smiles>CC(C)CC(=O)OC[C@H]1CCC(C2(C)CCCC(C)(C)C2)=C2C[C@H]3C(=O)O[C@H]3[C@H]21</smiles>

( \pm )-spongiolactone, $53 \%$

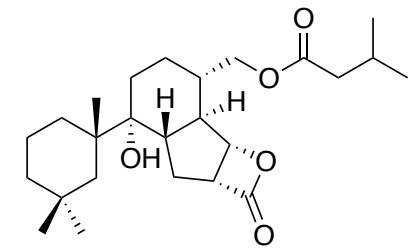

220, $39 \%, d r=3: 1$

$$
\underset{\substack{\mathrm{CH}_{2} \mathrm{Cl}_{2} \\ 0 \text { to } 23^{\circ} \mathrm{C}}}{\stackrel{\mathrm{SOCl}_{3} \mathrm{~N}}{\longrightarrow}}
$$

>

\subsubsection{4 (-)-Curcumanolide $A$ and (-)-Curcumalactone}

Desymmetrization of diones was shown to deliver fused $\beta$-lactone $\mathbf{2 2 2}$ with excellent enantiomeric excesses via an asymmetric nucleophile (Lewis base)-catalyzed aldol lactonization of 221. BaeyerVilliger oxidation of the tricyclic lactone followed by dyotropic 1,2-acyl migration led to bislactone 224, a common intermediate in the synthesis of (-)-curcumanolide $A$ and (-)-curcumalactone. ${ }^{156-158}$

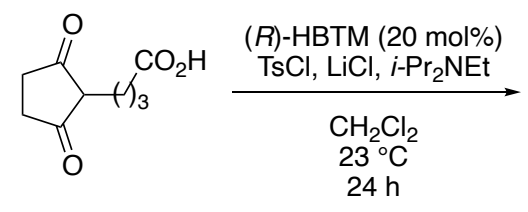

221

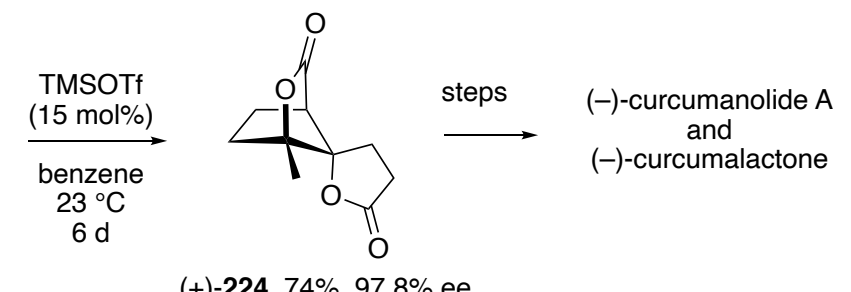

(+)-224, 74\%, 97.8\% ee

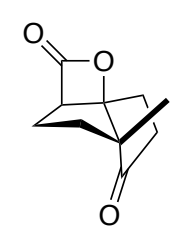

$(-)-222,65 \%$ $\mathrm{dr}>19: 1,98 \%$ ee

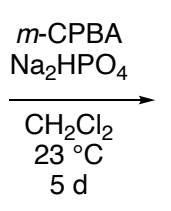

(-)-223, 45\%
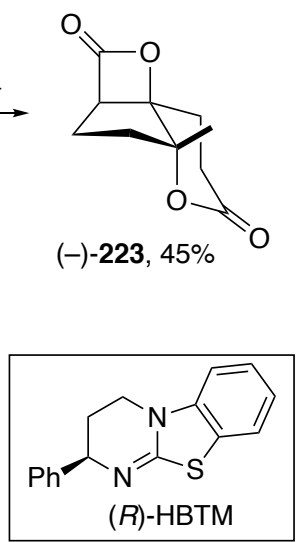

$<$ Scheme 63 near here>

A similar strategy was used by Romo for several other natural products, such as ( \pm )-salinosporamide $A,{ }^{159}( \pm)$-cinnabaramide $A^{160}$ and (+)-omphadiol. ${ }^{161}$ 


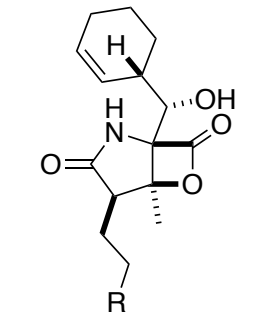

( \pm )-salinosporamide $\mathrm{A}, \mathrm{R}=\mathrm{Cl}$

$( \pm)$-cinnabaramide $A, R=B u$

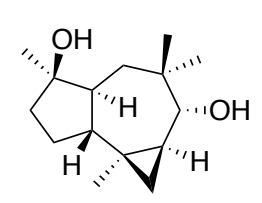

(+)-omphadiol

<Scheme 64 near here>

\subsubsection{5 (+)-Dictyoxetane}

(+)-Dictyoxetane was isolated from a brown alga Dictyota dichotoma (Indian ocean) in 1985 and was found to possess a unique oxetane motif embedded in a 2,7-dioxatricyclo[4.2.1.0 $\left.{ }^{3,8}\right]$ nonane ring system. ${ }^{162}$ Magauer reported the very first synthesis of (+)-dictyoxetane in 2016. ${ }^{163,164}$ The challenging oxetane in $\mathbf{2 2 6}$ was constructed through the intramolecular displacement of an allylic mesylate, generated from $\mathbf{2 2 5}$, under basic conditions in $88 \%$ yield.

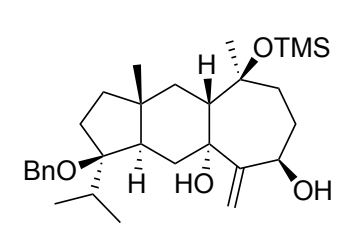

225

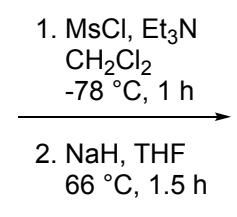

$\mathrm{NaH}, \mathrm{THF}$
$66^{\circ} \mathrm{C}, 1.5 \mathrm{~h}$

$<$ Scheme 65 near here>

\subsubsection{6 (+)-Pleuromutilin}

Carbonyl-alkyne metathesis reactions ${ }^{80-85}$ have found numerous applications in the context of total synthesis of natural products and only a few examples will be discussed here. During the course of investigations aiming at the total synthesis of (+)-pleuromutilin, Herzon reported the unexpected formation of the transient intermediate fused oxetene $\mathbf{2 3 0}$ from the oxidative cyclization/C-O reductive elimination of yne-aldehyde 227 using $\mathrm{Ni}(\mathrm{COD})_{2}$ (40 mol\%), 4,5-dichloro-1,3-bis(2,6diisopropylphenyl)-1,3-dihydro-2H-imidazol-2-ylidene (40 mol\%) and triisopropylsilane as a reductant. ${ }^{165}$ 


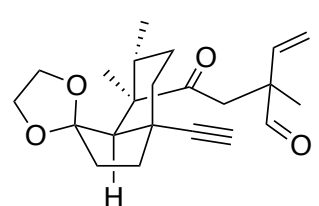

227

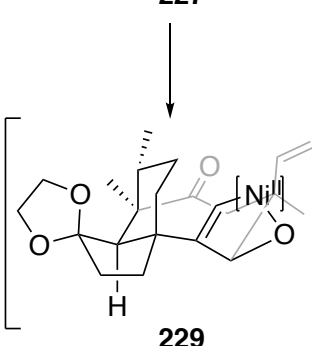

229

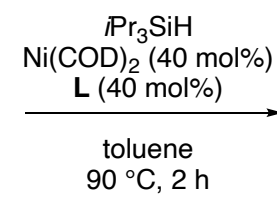

$90{ }^{\circ} \mathrm{C}, 2 \mathrm{~h}$

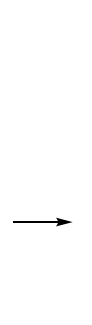

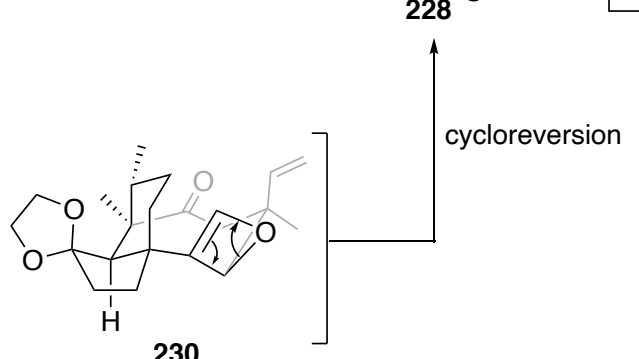

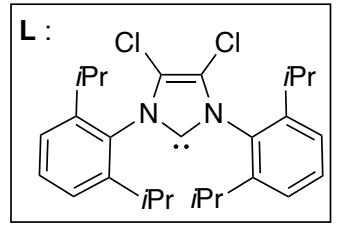

230

$<$ Scheme 66 near here>

\subsubsection{Phomopsidone A, Artoheterophyllin E, Morusalbin B, Fusariumin D}

Shen reported the isolation of phomopsidone A in 2014 from the mangrove endophytic fungus Phomopsis sp. A123. ${ }^{166}$ The same year, artoheterophyllin E was isolated from the wood of Artocarpus heterophyllus, an evergreen fruit tree collected in Hainan province (PR China). ${ }^{167}$ Although extensive NMR and mass spectrometry experiments were performed and discussed, the structure of these compounds are questionable in light of the well-known instability of benzoxetes that are in equilibrium with their thermodynamically favored ortho-quinoïds valence isomers. Indeed, phomopsidone A was recently suggested to possess excelsione's structure. ${ }^{13}$

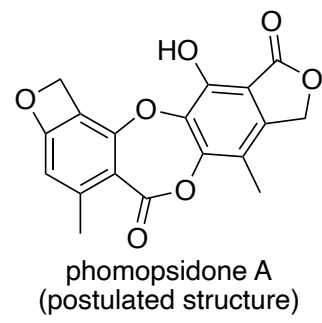

$<$ Scheme 67 near here><smiles>Oc1ccc2c(c1)OC(CC1Oc3cc(O)ccc31)O2</smiles>

artoheterophylline $\mathrm{E}$<smiles>Cc1cc(O)c(CO)c2c1Oc1c(C)c3c(c(O)c1OC2=O)C(=O)OC3</smiles>

excelsione

Morusalbin B was extracted from the root bark of M. alba L. (Moraceae) in the Republic of Korea. Its quite complex structure is proposed to possess a fused benzoxete. ${ }^{168}$ Recently, Zhang and Wang extracted from the fermentation broth of Fusarium oxysporum ZZP-R1 two new antimicrobial agents, among which Fusariumin D. ${ }^{169}$ The structure of the latter was recently proposed to actually be a 4pyranone scaffold. ${ }^{13}$<smiles>CC1=CC23OCC4(C1)c1ccc(O)cc1C4(c1ccc(O)cc1O)Oc1cc(-c4cc5ccc(O)cc5o4)cc(c12)O3</smiles>

Morusalbin B

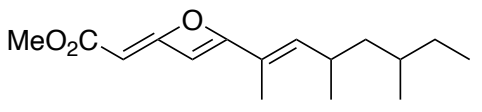

Fusariumin D

$<$ Scheme 68 near here> 


\subsubsection{8 (-)-Mitrephorone A}

Mitrephorone A is a member of the family of ent-trachylobanes which was isolated in 2005 from Mitrephora glabra, a Bornean shrub. Its structure features a highly congested hexacycle with an embedded oxetane. The central oxetane of mitrephorone A was prepared thanks to an impressive oxidative 4-exo-trig cyclization of a hydroxy enol ketone, derived from 231, activated with Koser's reagent. ${ }^{170}$ An alternative synthetic blueprint was reported a year later, ${ }^{171}$ featuring a direct conversion of mitrephorone $\mathrm{B}$ to mitrephorone $\mathrm{A}$ via a bioinspired $\mathrm{C}-\mathrm{H}$ oxidation with White-Chen catalyst. Electrochemical oxidation or photocatalyzed formation of the oxetane lead to lower yields.

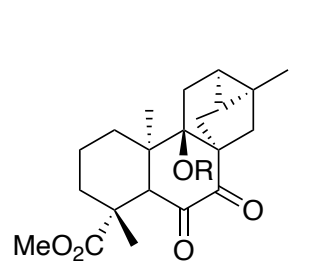

231, $R=$ TES

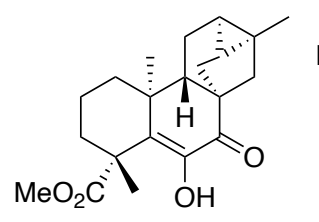

mitrephorone B, $60 \%$

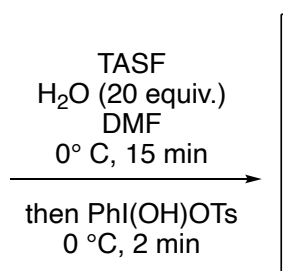

$\mathrm{Fe}(R, R)$-PDP (25 mol\%)

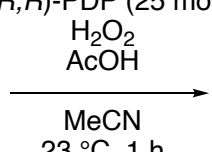

$23^{\circ} \mathrm{C}, 1 \mathrm{~h}$
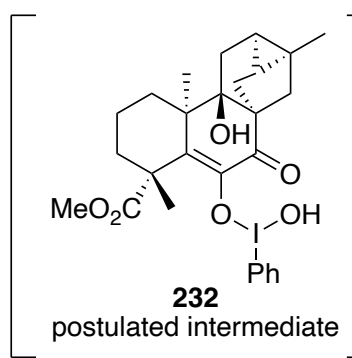

postulated intermediate

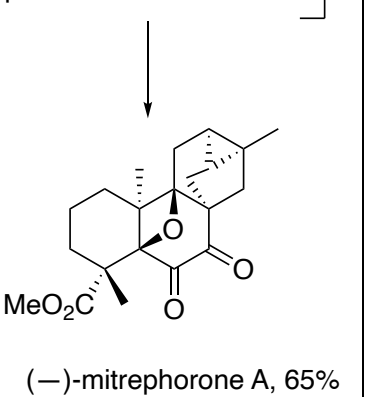

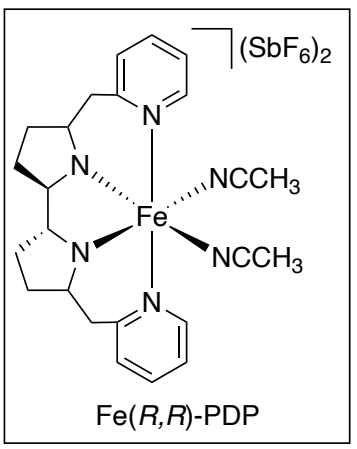

$<$ Scheme 69 near here>

\section{Acknowledgments}

The authors thank the Universite de Strasbourg, the Universite de Haute-Alsace, the CNRS and the Indo-French Centre for the Promotion of Advanced Research (IFCPAR, project 6105-1) for their financial support.

\section{References}

\footnotetext{
${ }^{1}$ Arumugam, S.; Popik, V. V. J. Am. Chem. Soc. 2009, 131, 11892-11899.

${ }^{2}$ Novak, I.; Harrison, L. J.; Li, W.; Kovač, B. J. Phys. Chem. A 2007, 111, 2619-2624.

${ }^{3}$ Migani, A.; Blancafort, L.; Robb, M. A.; DeBellis, A. D. J. Am. Chem. Soc. 2008, 130, 6932-6933

${ }^{4}$ Friedrich, L. E.; Schuster, G. B. J. Am. Chem. Soc. 1971, 93, 4602-4604.

5 Jaccob, M.; Sheeba Jem, I.; Giri, S.; Venuvanalingam, P.; Chattaraj, P. K. J. Phys. Org. Chem. 2011, 24, 460-465.

${ }^{6}$ Jayaprakash, S.; Jeevanandam, J.; Subramani, K. J. Mol. Model. 2014, 20, 2494.
} 
${ }^{7}$ Guo, X.; Wang, J.; Li, C.-J. J. Am. Chem. Soc. 2009, 131, 15092-15093.

${ }^{8}$ Varela, J. A.; González-Rodríguez, C.; Rubín, S. G.; Castedo, L.; Saá, C. J. Am. Chem. Soc. 2006, 128, 9576-9577.

${ }^{9}$ Zhang, J.; Shen, W.; Liu, R.; Yu, Y.; Wu, H.; Li, M. Int. J. Quantum Chem. 2009, 109, 679-687.

${ }^{10}$ Tomberg, A.; Kundu, S.; Zhou, F.; Li, C.-J.; Moitessier, N. ACS Omega 2018, 3, 3218-3227.

${ }^{11}$ Yabuno, Y.; Hiraga, Y.; Takagi, R.; Abe, M. J. Am. Chem. Soc. 2011, 133, 2592-2604.

12 Xu, T.; Yang, Q.; Li, D.; Dong, J.; Yu, Z.; Li, Y. Chem. Eur. J. 2010, 16, 9264-9272.

${ }^{13}$ Kutateladze, A. G.; Holt, T.; Reddy, D. S. J. Org. Chem. 2019, 84, 7575-7586.

${ }^{14}$ Yang, J.; Shan, X.; Zhang, Z.; Tang, Y.; Zhao, M.; Chen, X. J. Phys. Chem. A 2014, 118, 11780-11786.

15 Tang, Y.; Shan, X.; Yang, J.; Niu, S.; Zhang, Z.; Watanabe, N.; Yamazaki, M.; Takahashi, M.; Chen, X. J. Phys. Chem. A 2016, 120, 6855-6863.

${ }^{16}$ Harris, S. J.; Murdock, D.; Grubb, M. P.; Clark, I. P.; Greetham, G. M.; Towrie, M.; Ashfold, M. N. R. J. Phys. Chem. A 2014, 118, 10240-10245.

${ }^{17}$ Koch, R.; Blanch, R. J.; Wentrup, C. J. Org. Chem. 2014, 79, 6978-6986.

18 Meier, H. Molecules 2012, 17, 1548-1570.

19 Balaban, A. T.; Greer, A.; Liebman, J. F. In Advances in Heterocyclic Chemistry; Katritzky, A. R., Ed.; Academic Press, 2014; Vol. 113, 111-142.

${ }^{20}$ Hideo, T.; Takeshi, M. Chem. Lett. 1997, 26, 399-400.

${ }^{21}$ Shanks, D.; Frisell, H.; Ottosson, H.; Engman, L. Org. Biomol. Chem. 2006, 4, 846-852.

22 Škalamera, Đ.; Antol, I.; Mlinarić-Majerski, K.; Vančik, H.; Phillips, D. L.; Ma, J.; Basarić, N. Chem. Eur. J. 2018, 24, 9426-9435.

${ }^{23}$ Chen, S.; Zhang, Y.; Zhao, C.; Ren, F.; Liu, X.; Che, Y. Fitoterapia 2014, 99, 236-242.

24 Chen, S.; Zhang, Y.; Niu, S.; Liu, X.; Che, Y. J. Nat. Prod. 2014, 77, 1513-1518.

${ }^{25}$ Wang, J.-S.; Zhang, Y.; Wang, X.-B.; Kong, L.-Y. Tetrahedron 2012, 68, 3963-3971.

${ }^{26}$ Zou, J.; Pan, L.; Li, Q.; Zhao, J.; Pu, J.; Yao, P.; Gong, N.; Lu, Y.; Kondratyuk, T. P.; Pezzuto, J. M.et al. Org. Lett. 2011, 13, 1406-1409.

27 Sautier, B.; Lyons, S. E.; Webb, M. R.; Procter, D. J. Org. Lett. 2012, 14, 146-149.

${ }^{28}$ Griesbeck, A. G.; Franke, M.; Neudörfl, J.; Kotaka, H. Beilstein J. Org. Chem. 2011, 7, 127-134.

${ }^{29}$ Xin, H.; Zhu, X.; Yan, H.; Song, X. Tetrahedron Lett. 2013, 54, 3325-3328.

${ }^{30}$ Schmidt, W.; Jones, P. G.; Herrmann, J.; Müller, R.; Schulz, S. Synlett 2017, 13, 467-470.

${ }^{31}$ Monleón, A.; Glaus, F.; Vergura, S.; Jørgensen, K. A. Angew. Chem. Int. Ed. 2016, 55, 2478-2482.

32 Conboy, D.; Mirallai, S. I.; Craig, A.; McArdle, P.; Al-Kinani, A. A.; Barton, S.; Aldabbagh, F. J. Org. Chem. 2019, 84, 9811-9818.

${ }^{33}$ Hao, X.; Liu, X.; Li, W.; Tan, F.; Chu, Y.; Zhao, X.; Lin, L.; Feng, X. Org. Lett. 2014, 16, 134-137.

${ }^{34}$ Ahmad, S.; Yousaf, M.; Mansha, A.; Rasool, N.; Zahoor, A. F.; Hafeez, F.; Rizvi, S. M. A. Synth. Commun. 2016, 46, 1397-1416.

${ }^{35}$ Pritchard, J. G.; Long, F. A. J. Am. Chem. Soc. 1958, 80, 4162-4165.

${ }^{36}$ Ringnér, B.; Sunner, S.; Watanabe, H. Acta. Chem. Scand. 1971, 25, 141-146.

${ }^{37}$ Eigenmann, H. K.; Golden, D. M.; Benson, S. W. J. Phys. Chem. 1973, 77, 1687-1691.

${ }^{38}$ Sella, A.; Basch, H.; Hoz, S. J. Am. Chem. Soc. 1996, 118, 416-420.

${ }^{39}$ Wolk, J. L.; Sprecher, M.; Basch, H.; Hoz, S. Org. Biomol. Chem. 2004, 2, 1065-1069.

${ }^{40}$ Wolk, J. L.; Hoz, T.; Basch, H.; Hoz, S. J. Org. Chem. 2001, 66, 915-918.

${ }^{41}$ Banks, H. D. J. Org. Chem. 2003, 68, 2639-2644.

42 Sawicka, D.; Houk, K. N. Mol. Model. 2000, 6, 158-165.

${ }^{43}$ Rosenberg, M. G.; Billing, P.; Brecker, L.; Brinker, U. H. J. Org. Chem. 2014, 79, 8786-8799.

${ }^{44}$ Stedjan, M. K.; Augspurger, J. D. J. Phys. Org. Chem. 2015, 28, 298-303. 
${ }^{45}$ Taskinen, E. J. Phys. Org. Chem. 2009, 22, 42-51.

${ }^{46}$ Goldsmith, C. F.; Magoon, G. R.; Green, W. H. J. Phys. Chem. A 2012, 116, 9033-9057.

${ }^{47}$ Wuitschik, G.; Carreira, E. M.; Wagner, B.; Fischer, H.; Parrilla, I.; Schuler, F.; Rogers-Evans, M.; Müller, K. J. Med. Chem. 2010, 53, 3227-3246.

${ }^{48}$ Burkhard, J. A.; Wuitschik, G.; Rogers-Evans, M.; Müller, K.; Carreira, E. M. Angew. Chem. Int. Ed. 2010, 49, 9052-9067.

49 Wuitschik, G.; Rogers-Evans, M.; Buckl, A.; Bernasconi, M.; Märki, M.; Godel, T.; Fischer, H.; Wagner, B.; Parrilla, I.; Schuler, F.et al. Angew. Chem. Int. Ed. 2008, 47, 4512-4515.

${ }^{50}$ Wuitschik, G.; Rogers-Evans, M.; Müller, K.; Fischer, H.; Wagner, B.; Schuler, F.; Polonchuk, L.; Carreira, E. M. Angew. Chem. Int. Ed. 2006, 45, 7736-7739.

51 Job, A.; Janeck, C. F.; Bettray, W.; Peters, R.; Enders, D. Tetrahedron 2002, 58, 2253-2329.

52 Geden, J. V.; Beasley, B. O.; Clarkson, G. J.; Shipman, M. J. Org. Chem. 2013, 78, 12243-12250.

${ }^{53}$ Vo, C.-V. T.; Mikutis, G.; Bode, J. W. Angew. Chem. Int. Ed. 2013, 52, 1705-1708.

${ }^{54}$ Siau, W.-Y.; Bode, J. W. J. Am. Chem. Soc. 2014, 136, 17726-17729.

${ }^{55}$ Vo, C.-V. T.; Luescher, M. U.; Bode, J. W. Nat. Chem. 2014, 6, 310-314.

${ }^{56}$ Geoghegan, K.; Bode, J. W. Org. Lett. 2015, 17, 1934-1937.

${ }^{57}$ Brady, P. B.; Carreira, E. M. Org. Lett. 2015, 17, 3350-3353.

${ }^{58}$ Ruider, S. A.; Müller, S.; Carreira, E. M. Angew. Chem. Int. Ed. 2013, 52, 11908-11911.

${ }^{59}$ Curti, C.; Battistini, L.; Sartori, A.; Zanardi, F. Chem. Rev. 2020, 120, 2448-2612.

${ }^{60}$ Dieckmann, A.; Breugst, M.; Houk, K. N. J. Am. Chem. Soc. 2013, 135, 3237-3242.

${ }^{61}$ Nassoy, A.-C.; Raubo, P.; Harrity, J. P. A. Tetrahedron Lett. 2013, 54, 3094-3096.

${ }^{62}$ Corey, E. J.; Streith. J. J. Am. Chem. Soc. 1964, 86, 950-951.

${ }^{63}$ Coote, S. C. Eur. J. Org. Chem. 2020, 1405-1423.

${ }^{64}$ Frébault, F.; Luparia, M.; Oliveira, M. T.; Goddard, R.; Maulide, N. Angew. Chem. Int. Ed. 2010, 49, 5672-5676.

${ }^{65}$ Gutekunst, W. R.; Baran, P. S. J. Am. Chem. Soc. 2011, 133, 19076-19079.

${ }^{66}$ Audisio, D.; Luparia, M.; Oliveira, M. T.; Klütt, D.; Maulide, N. Angew. Chem. Int. Ed. 2012, 51, 7314-7317.

67 Souris, C.; Frébault, F.; Patel, A.; Audisio, D.; Houk, K. N.; Maulide, N. Org. Lett. 2013, 15, 3242-3245.

68 Souris, C.; Luparia, M.; Frébault, F.; Audisio, D.; Farès, C.; Goddard, R.; Maulide, N. Chem. Eur. J. 2013, 19, 6566-6570.

${ }^{69}$ Souris, C.; Misale, A.; Chen, Y.; Luparia, M.; Maulide, N. Org. Lett. 2015, 17, 4486-4489.

70 Misale, A.; Niyomchon, S.; Maulide, N. Acc. Chem. Res. 2016, 49, 2444-2458.

${ }^{71}$ Bauer, A.; Nam, J.-H.; Maulide, N. Synlett 2019, 30, 413-416.

72 Yamashita, T.; Nishikawa, H.; Kawamoto, T. Tetrahedron 2019, 75, 617-623.

${ }^{73}$ Cabré, A.; Rafael, S.; Sciortino, G.; Ujaque, G.; Verdaguer, X.; Lledós, A.; Riera, A. Angew. Chem. Int. Ed. 2020, 59, 7521-7527.

${ }^{74}$ Ghosh, A. K.; Robinson, W. L. J. Org. Chem. 2019, 84, 9801-9805.

75 Melis, N.; Luridiana, A.; Guillot, R.; Secci, F.; Frongia, A.; Boddaert, T.; Aitken, D. J. Eur. J. Org. Chem. 2017, 2017, 5896-5902.

${ }^{76}$ Nicolle, S. M.; Nortcliffe, A.; Bartrum, H. E.; Lewis, W.; Hayes, C. J.; Moody, C. J. Chem. Eur. J. 2017, 23, 13623-13627.

77 D'Auria, M. Photochem. Photobiol. Sci. 2019, 18, 2297-2362.

78 Mulzer, J.; Zippel, M.; Brüntrup, G. Angew. Chem. Int. Ed. 1980, 19, 465-466.

${ }^{79}$ Wu, X.; Hao, L.; Zhang, Y.; Rakesh, M.; Reddi, R. N.; Yang, S.; Song, B.-A.; Chi, Y. R. Angew. Chem. Int. Ed. 2017, 56, 4201-4205.

${ }^{80}$ Becker, M. R.; Reid, J. P.; Rykaczewski, K. A.; Schindler, C. S. ACS Catal. 2020, 10, 4387-4397. 
${ }^{81}$ Hanson, C. S.; Psaltakis, M. C.; Cortes, J. J.; Siddiqi, S. S.; Devery, J. J. J. Org. Chem. 2020, 85, 820-832.

82 McFarlin, A. T.; Watson, R. B.; Zehnder, T. E.; Schindler, C. S. Adv. Synth. Catal. 2020, 362, 365-369.

${ }^{83}$ Riehl, P. S.; Nasrallah, D. J.; Schindler, C. S. Chem. Sci. 2019, 10, 10267-10274.

${ }^{84}$ Becker, M. R.; Watson, R. B.; Schindler, C. S. Chem. Soc. Rev. 2018, 47, 7867-7881.

85 Saito, A.; Tateishi, K. Heterocycles 2016, 92, 607.

${ }^{86} \mathrm{Jin}, \mathrm{T} . ;$ Yamamoto, Y. Org. Lett. 2007, 9, 5259-5262.

${ }^{87}$ Liu, L.; Xu, B.; Hammond, G. B. Beilstein J. Org. Chem. 2011, 7, 606-614.

${ }^{88}$ Escalante, L.; González-Rodríguez, C.; Varela, J. A.; Saá, C. Angew. Chem. Int. Ed. 2012, 51, 12316-12320.

${ }^{89}$ Yeh, M.-C. P.; Lin, M.-N.; Hsu, C.-H.; Liang, C.-J. J. Org. Chem. 2013, 78, 12381-12396.

${ }^{90}$ Zhao, W.; Li, Z.; Sun, J. J. Am. Chem. Soc. 2013, 135, 4680-4683.

${ }^{91}$ Cheng, D.; Ling, F.; Zheng, C.; Ma, C. Org. Lett. 2016, 18, 2435-2438.

92 Yoshioka, E.; Kohtani, S.; Miyabe, H. Org. Lett. 2010, 12, 1956-1959.

${ }^{93}$ Yoshida, H.; Ito, Y.; Ohshita, J. Chem. Commun. 2011, 47, 8512-8514.

${ }^{94}$ Zhou, C.; Wang, J.; Jin, J.; Lu, P.; Wang, Y. Eur. J. Org. Chem. 2014, 2014, 1832-1835.

${ }^{95}$ Fujishima, T.; Suenaga, T.; Nozaki, T. Tetrahedron Lett. 2014, 55, 3805-3808.

${ }^{96}$ Fujishima, T.; Nozaki, T.; Suenaga, T. Bioorg. Med. Chem. 2013, 21, 5209-5217.

97 Suenega, T.; Fujishima, T. Tetrahedron 2018, 74, 1461-1467.

98 Trost, B. M.; Masters, J. T. Chem. Soc. Rev. 2016, 45, 2212-2238.

${ }^{99}$ Deng, H.; Jia, R.; Yang, W.-L.; Yu, X.; Deng, W.-P. Chem. Commun. 2019, 55, 7346-7349.

100 Jones, B.; Proud, M.; Sridharan, V. Tetrahedron Lett. 2016, 57, 2811-2813.

${ }^{101}$ Keshipeddy, S.; Martínez, I.; Castillo, B. F.; Morton, M. D.; Howell, A. R. J. Org. Chem. 2012, 77, 7883-7890.

102 Malapit, C. A.; Chitale, S. M.; Thakur, M. S.; Taboada, R.; Howell, A. R. J. Org. Chem. 2015, 80, 5196-5209.

${ }^{103}$ Wu, D.-D.; Huang, C.-M.; Wu, Y.-H.; Fun, H.-K.; Xu, J.-H.; Zhang, Y. RSC Advances 2013, 3, 7529-7536.

104 Nakazaki, A.; Nakane, Y.; Ishikawa, Y.; Nishikawa, T. Heterocycles 2015, 91, 1157-1163.

${ }^{105}$ Fréneau, M.; Hoffmann, N. J. Photochem. Photobiol. C: Photochem. Rev. 2017, 33, 83-108.

106 Ralph, M.; Ng, S.; Booker-Milburn, K. I. Org. Lett. 2016, 18, 968-971.

${ }^{107}$ Franceschi, P.; Mateos, J.; Vega Peñaloza, A.; Dell'Amico, L. Eur. J. Org. Chem. 2020, 6718-6722.

108 Poscharny, K.; Fabry, D. C.; Heddrich, S.; Sugiono, E.; Liauw, M. A.; Rueping, M. Tetrahedron 2018, 74, 31713175.

109 Flores, D. M.; Schmidt, V. A. J. Am. Chem. Soc. 2019, 141, 8741-8745.

110 Buendia, J.; Chang, Z.; Eijsberg, H.; Guillot, R.; Frongia, A.; Secci, F.; Xie, J.; Robin, S.; Boddaert, T.; Aitken, D. J. Angew. Chem. Int. Ed. 2018, 57, 6592-6596.

111 Huang, C.; Yu, H.; Miao, Z.; Zhou, J.; Wang, S.; Fun, H.-K.; Xu, J.; Zhang, Y. Org. Biomol. Chem. 2011, 9, 36293631.

112 Kumarasamy, E.; Raghunathan, R.; Kandappa, S. K.; Sreenithya, A.; Jockusch, S.; Sunoj, R. B.; Sivaguru, J. J. Am. Chem. Soc. 2017, 139, 655-662.

113 Wang, W.; Zhang, W.-J.; Wang, L.; Quah, C. K.; Fun, H.-K.; Xu, J.-H.; Zhang, Y. J. Org. Chem. 2013, 78, 62116222.

${ }^{114}$ Kaeobamrung, J.; Bode, J. W. Org. Lett. 2009, 11, 677-680.

115 Mukherjee, S.; Mondal, S.; Patra, A.; Gonnade, R. G.; Biju, A. T. Chem. Commun. 2015, 51, 9559-9562.

${ }^{116}$ Zhang, J.-Q.; Li, N.-K.; Yin, S.-J.; Sun, B.-B.; Fan, W.-T.; Wang, X.-W. Adv. Synth. Catal. 2017, 359, $1541-1551$.

117 Cohen, D. T.; Eichman, C. C.; Phillips, E. M.; Zarefsky, E. R.; Scheidt, K. A. Angew. Chem. Int. Ed. 2012, 51, 7309-7313.

118 Johnston, R. C.; Cohen, D. T.; Eichman, C. C.; Scheidt, K. A.; Ha-Yeon Cheong, P. Chem. Sci. 2014, 5, 19741982. 
${ }^{119}$ Cohen, D. T.; Johnston, R. C.; Rosson, N. T.; Cheong, P. H.-Y.; Scheidt, K. A. Chem. Commun. 2015, 51, 26902693.

${ }^{120}$ Candish, L.; Forsyth, C. M.; Lupton, D. W. Angew. Chem. Int. Ed. 2013, 52, 9149-9152.

${ }^{121}$ Candish, L.; Lupton, D. W. J. Am. Chem. Soc. 2013, 135, 58-61.

122 Bera, S.; Samanta, R. C.; Daniliuc, C. G.; Studer, A. Angew. Chem. Int. Ed. 2014, 53, 9622-9626.

123 Liu, G.; Shirley, M. E.; Van, K. N.; McFarlin, R. L.; Romo, D. Nat. Chem. 2013, 5, 1049-1057.

124 Leeder, A. J.; Heap, R. J.; Brown, L. J.; Franck, X.; Brown, R. C. D. Org. Lett. 2016, 18, 5971-5973.

125 Davis, O. A.; Croft, R. A.; Bull, J. A. Chem. Commun. 2015, 51, 15446-15449.

${ }^{126}$ Davis, O. A.; Bull, J. A. Angew. Chem. Int. Ed. 2014, 53, 14230-14234.

${ }^{127}$ Lekkala, R.; Lekkala, R.; Moku, B.; Rakesh, K. P.; Qin, H.-L. Beilstein J. Org. Chem. 2019, 15, 976-980.

${ }^{128}$ Xu, R.; Czarniecki, M.; Man, J. d.; Pan, J.; Qiang, L.; Root, Y.; Ying, S.; Su, J.; Sun, X.; Zhang, Y.; Hu, T.; Chen, S.H. Tetrahedron Lett. 2011, 52, 3266-3270.

${ }^{129}$ For a review on spiro-piperidines, see: Griggs, S. D.; Tape, D. T.; Clarke, P. A. Org. Biomol. Chem. 2018, 16, 6620-6633.

130 Yoshioka, S.; Nagatomo, M.; Inoue, M. Org. Lett. 2015, 17, 90-93.

131 Lajkiewicz, N. J.; Cognetta, A. B.; Niphakis, M. J.; Cravatt, B. F.; Porco, J. A. J. Am. Chem. Soc. 2014, 136, 2659-2664.

132 Shenvi, R. A.; Corey, E. J. J. Am. Chem. Soc. 2009, 131, 5746-5747.

133 Rullière, P.; Cannillo, A.; Grisel, J.; Cividino, P.; Sébastien, C.; Poisson, J.-F. Org. Lett. 2018, 20, 4558-4561.

${ }^{134}$ Fukuda, T.; Sugiyama, K.; Arima, S.; Harigaya, Y.; Nagamitsu, T.; Ōmura, S. Org. Lett. 2008, 10, 4239-4242.

135 Satoh, N.; Yokoshima, S.; Fukuyama, T. Org. Lett. 2011, 13, 3028-3031.

${ }^{136}$ Gholami, H.; Kulshrestha, A.; Favor, O. K.; Staples, R. J.; Borhan, B. Angew. Chem. Int. Ed. 2019, 58, 1011010113.

137 Marx, L. B.; Burton, J. W. Chem. Eur. J. 2018, 24, 6747-6754.

${ }^{138}$ Armitage, I.; Elliott, E. L.; Hicks, F.; Langston, M.; McCarron, A.; McCubbin, Q. J.; O’Brien, E.; Stirling, M.; Zhu, L. Org. Proc. Res. Dev. 2015, 19, 1299-1307.

139 Tong, G.; Liu, Z.; Li, P. Org. Lett. 2014, 16, 2288-2291.

140 Nicolle, S. M.; Nortcliffe, A.; Bartrum, H. E.; Lewis, W.; Hayes, C. J.; Moody, C. J. Chem. Eur. J. 2017, 23, 13623-13627.

${ }^{141}$ Wang, J.-C.; Zhang, Y.; Xu, Z.-J.; Lo, V. K.-Y.; Che, C.-M. ACS Catal. 2013, 3, 1144-1148.

142 Huang, J.-M.; Yang, C.-S.; Tanaka, M.; Fukuyama, Y. Tetrahedron 2001, 57, 4691-4698.

143 Birman, V. B.; Danishefsky, S. J. J. Am. Chem. Soc. 2002, 124, 2080-2081.

${ }^{144}$ Chen, J.; Gao, P.; Yu, F.; Yang, Y.; Zhu, S.; Zhai, H. Angew. Chem. Int. Ed. 2012, 51, 5897-5899.

${ }^{145}$ He, W.; Huang, J.; Sun, X.; Frontier, A. J. J. Am. Chem. Soc. 2008, 130, 300-308.

146 Ganji, P.; Ibrahim, H. Chem. Commun. 2012, 48, 10138-10140.

${ }^{147}$ Hubbell, A. K.; LaPointe, A. M.; Lamb, J. R.; Coates, G. W. J. Am. Chem. Soc. 2019, 141, 2474-2480.

148 Lam, S. M.; Wong, W.-t.; Chiu, P. Org. Lett. 2017, 19, 4468-4471.

149 Vil, V.; Terent'ev, A. O.; Al Quntar, A. A. A.; Gloriozova, T. A.; Savidov, N.; Dembitsky, V. M. Appl. Microbiol. Biotechnol. 2019, 103, 2449-2467.

${ }^{150}$ Fujita, S.; Nishikawa, K.; Iwata, T.; Tomiyama, T.; Ikenaga, H.; Matsumoto, K.; Shindo, M. Chem. Eur. J. 2018, 24, 1539-1543.

${ }^{151}$ Shindo, M.; Sato, Y.; Shishido, K. Tetrahedron 1998, 54, 2411-2422.

152 Schmiedel, V. M.; Hong, Y. J.; Lentz, D.; Tantillo, D. J.; Christmann, M. Angew. Chem. Int. Ed. 2018, 57, 24192422.

153 Harvey, N. L.; Krysiak, J.; Chamni, S.; Cho, S. W.; Sieber, S. A.; Romo, D. Chem. Eur. J. 2015, 21, 1425-1428. 
154 Cortez, G. S.; Tennyson, R. L.; Romo, D. J. Am. Chem. Soc. 2001, 123, 7945-7946.

155 Mondal, S.; Mukherjee, S.; Das, T. K.; Gonnade, R.; Biju, A. T. ACS Catal. 2017, 7, 3995-3999.

156 Leverett, C. A.; Purohit, V. C.; Johnson, A. G.; Davis, R. L.; Tantillo, D. J.; Romo, D. J. Am. Chem. Soc. 2012, $134,13348-13356$.

157 Liu, G.; Shirley, M. E.; Romo, D. J. Org. Chem. 2012, 77, 2496-2500.

158 Kong, W.; Romo, D. J. Org. Chem. 2017, 82, 13161-13170.

159 Nguyen, H.; Ma, G.; Romo, D. Chem. Commun. 2010, 46, 4803-4805.

160 Ma, G.; Nguyen, H.; Romo, D. Org. Lett. 2007, 9, 2143-2146.

161 Liu, G.; Romo, D. Angew. Chem. Int. Ed. 2011, 50, 7537-7540.

162 Pullaiah, K. C.; Surapaneni, R. K.; Rao, C. B.; Albizati, K. F.; Sullivan, B. W.; Faulkner, D. J.; He, C. H.; Clardy, J. J. Org. Chem. 1985, 50, 3665-3666.

163 Hugelshofer, C. L.; Magauer, T. J. Am. Chem. Soc. 2016, 138, 6420-6423.

164 Hugelshofer, C. L.; Magauer, T. Chem. Eur. J. 2016, 22, 15125-15136.

165 Zeng, M.; Murphy, S. K.; Herzon, S. B. J. Am. Chem. Soc. 2017, 139, 16377-16388.

${ }^{166}$ Zhang, W.; Xu, L.; Yang, L.; Huang, Y.; Li, S.; Shen, Y. Fitoterapia 2014, 96, 146-151.

167 Zheng, Z.-P.; Xu, Y.; Qin, C.; Zhang, S.; Gu, X.; Lin, Y.; Xie, G.; Wang, M.; Chen, J. J. Agr. Food Chem. 2014, 62, 5519-5527.

168 Ha, M. T.; Seong, S. H.; Nguyen, T. D.; Cho, W.-K.; Ah, K. J.; Ma, J. Y.; Woo, M. H.; Choi, J. S.; Min, B. S. Phytochem. 2018, 155, 114-125.

${ }^{169}$ Chen, J.; Bai, X.; Hua, Y.; Zhang, H.; Wang, H. Fitoterapia 2019, 134, 1-4.

${ }^{170}$ Richter, M. J. R.; Schneider, M.; Brandstätter, M.; Krautwald, S.; Carreira, E. M. J. Am. Chem. Soc. 2018, 140, 16704-16710.

${ }^{171}$ Wein, L. A.; Wurst, K.; Angyal, P.; Weisheit, L.; Magauer, T. J. Am. Chem. Soc. 2019, 141, 19589-19593. 